\title{
Toxoplasmose ocular adquirida Toxoplasmose ocular pós-natal
}

\author{
Acquired ocular toxoplasmosis \\ Post-birth ocular toxoplasmosis
}

Fernando Oréfice ${ }^{1}$, Ruy Cunha Filho², Alda Lúcia Barboza ${ }^{3}$, Juliana Lambert Oréfice ${ }^{4}$, Daniela Calucci ${ }^{5}$

\footnotetext{
'Doutor, Professor Titular da Universidade Federal de Minas Gerais - UFMG - Belo Horizonte (MG), Brasil; Diretor da Divisão de Uveíte do Centro Brasileiro de Ciências Visuais - CBCV - Belo Horizonte (MG), Brasil;

${ }^{2}$ Médico Estagiário do Centro Brasileiro de Ciências Visuais e do Serviço de Uveíte do Hospital São Geraldo do Hospital das Clinicas da Universidade Federal de Minas Gerais - UFMG - Belo Horizonte (MG), Brasil;

${ }^{3}$ Doutora da Universidade Federal de Minas Gerais - UFMG - Belo Horizonte (MG), Brasil;

${ }^{4}$ Doutora, Diretora da Divisão de Imagens do CBCV; Assistente voluntária do Serviço de Uveíte do Hospital São Geraldo do Hospital das Clínicas da Universidade Federal de Minas Gerais - UFMG - Belo Horizonte (MG), Brasil;

${ }^{5}$ Tecnóloga em Oftalmologia do CBCV - Centro Brasileiro de Ciências Visuais - CBCV - Belo Horizonte (MG), Brasil.
}

Recebido para publicação em: 30/4/2009 - Aceito para publicação em 24/3/2010 


\section{INTRODUCTION}

$\mathbf{T}$ The T.gondii, etiologic agent of toxoplasmosis, is an obligate intracellular protozoan, with worldwide distribution. This parasite has shown a wide geographic distribution and behaves as a high infectivity and low pathogenicity agent, as observed that half of the population is infected and only a reduced proportion of it presents the disease (Holland, 1999a). In Brazil, 50 to $83 \%$ of the adult population is soropositive for T.gondii (Oréfice; Bahia-Oliveira, 2005).

The most common presentation form of post-birth systemic toxoplasmosis (PNST) an asymptomatic one that happens in $80-90 \%$ of all cases (Akstein; Wilson; Teutsch, 1982;Mansur;Jones;Lempert,1978;Stagno;Dykes;Amos, 1980). The ocular compromise of this infection may occur during the acute phase or several years after the systemic disease, and in latency interval is quite variable. This characteristic makes the diagnosis of post-birth ocular toxoplasmosis (PNOT) difficult, as long as the cases with ocular compromising at the inactive stage of the disease can be misunderstood with late manifestation of congenital infection (Akstein; Wilson; Teutsch, 1982; Couvreur; Thulliez, 1996; Mansur; Jones; Lempert, 1978; Melamed, 1994).

Although two and five cases of PNOT reported of by Hogan (1958) and Hogan e Kimura (1964) respectively, Perkins (1973) considered that ocular involvement of post-birth systemic toxoplasmosis (PNST) occurs in 2-3\% of cases and that in United Kingdom, almost all cases of ocular toxoplasmosis had a congenital origin. Besides that, the complications of systemic toxoplasmosis are more frequent when central nervous system is involved. These conceptions prevailed for long years. Nevertheless, Glasner, Silveira and KruszonMoran (1992), Gilbert and Standford (2000) emphasized the relevance of post-birth systemic toxoplasmosis (PNST). Besides that, the high prevalence of postbirth infection showed in southern Brazil suggests that the post-birth infection may be a common form of transmission of the disease (Glasner; Silveira; KruszonMoran, 1992). Another study made in the same region proved that $8.3 \%$ of the individuals with post-birth infection, who have not developed retinochoroiditis, presented scar passed a period of 7 years (Silveira et al., 2001). Gilbert and Standfort (2000) reported that two thirds of the cases of ocular toxoplasmosis in the United Kingdom are from post-birth origin.

The PNST may cause serious consequences to immunosupressed individuals, fetus of pregnant women carrying negative serology of the disease and may cause irreversible damage to the vision, mainly when the optic nerve and macula are involved (Lieb et al., 2004).

The diagnosis of the systemic post-birth disease and the recognition of the origin of infection are essential to understand the basic mechanisms of the disease, principally for protection of high risk patients, to prevention planning programs and to guidance about therapeutic consequences (Bosch-Driessen; Rothova, 1999).

The specific treatment of PNOT consists in the use of pirimetamin, sulfadiazin and folinic acid. Whenever an intense inflammation occurs, the use of systemic corticosteroids is indicated. Thus, the precise diagnosis of PNST is quite important, once it is known that the use of steroids during parasythemia (with no specific drugs for toxoplasmosis) may cause severe destruction of the retina and uncontrolled dissemination of the infection (Ronday et al. 1995).

Outbreaks of PNST have been described in several countries (Burnett et al. 1998, Mansur; Jones; Lempert, 1978; Moura et al., 2006). In fact, speaking of epidemiology, the PNST has assumed an important role all over the world. It reasserts not only about the importance of diagnosis in the patient infected with the systemic disease, but also about the need of investigation of the origin $\mathrm{f}$ acute disease: how many persons were contaminated, when it happened and what were its complications. Luft and Remington (1984) proved that the acute toxoplasmic infection in family members of patients with lymphadenopathy caused by T.gondii is common. They also showed that toxoplasmosis can be found in groups or persons infected from the same origin (Akstein; Wilson; Teutsch, 1982; Gonçalves et al., 1995; Teutsch et al.,1979). Additionally, the presence of ocular toxoplasmosis has been verified in more than one brother / sister in the same family (Pinheiro; Oréfice, 1990; Silveira et al., 1988).

Recent studies have been discussing the true role of the post-birth systemic infection in ocular disease. Some authors (Bahia-Oliveira et al., 2003; Bowie et al., 1997; Burnett et al., 1998; Ross et al., 2001; Silveira et al., 2001) have suggested that the post-birth systemic infection might be an important cause of ocular toxoplasmosis.

Oréfice et al. (2009) evaluated cases with clinical, serologic and epidemiologic evidences of post-birth ocular toxoplasmosis and episodes of ocular affection as the only manifestation of the systemic infection where there were no other clinical evidences of PNST. Researches about this subject with such a large sample are rare in the world literature, once this is a difficult diagnosis disease and with cases of conflicting diagnosis (tables 1,2). 


\section{INTRODUÇÃO}

$\mathbf{O}$ T.gondii, agente etiológico da toxoplasmose, é um protozoário intracelular obrigatório, de distribuição mundial. O parasito tem ampla distribuição geográfica e comporta-se como agente de alta infecciosidade e baixa patogenicidade, visto que 50,0\% ou mais da população estão contaminados pelo T.gondii e apenas uma proporção reduzida apresenta a doença (Holland, 1999). No Brasil 50,0 a 83,0\% da população adulta é soropositivo (Oréfice; Bahia-Oliveira, 2005).

A forma de apresentação mais comum da toxoplasmose sistêmica pós-natal (TSPN) é a forma assintomática que acomete $80-90 \%$ dos casos (Akstein; Wilson; Teutsch, 1982; Mansur; Jones; Lempert, 1978; Stagno; Dykes; Amos, 1980). O comprometimento ocular nessa infecção pode ocorrer durante a fase aguda ou muitos anos após a doença sistêmica, sendo o intervalo de latência muito variável. Isso torna difícil o diagnóstico da toxoplasmose ocular pós-natal (TOPN), já que os casos com comprometimento ocular na fase inativa da doença podem ser confundidos com infecção congênita de aparecimento tardio (Akstein; Wilson; Teutsch, 1982; Couvreur;Thulliez, 1996; Mansur; Jones; Lempert, 1978; Melamed, 1994).

Apesar do relato de dois em cinco casos de TOPN descritos por Hogan (1958) e por Hogan e Kimura (1964), Perkins (1973), respectivamente afirmarem que o envolvimento ocular na TSPN ocorre em 2 a $3 \%$ dos casos e que no Reino Unido, quase todos os casos de toxoplasmose ocular eram de origem congênita. Ademais, que as complicações da toxoplasmose sistêmica são mais frequentes quando há envolvimento do SNC. Esses conceitos prevaleceram por vários anos. Entretanto, Glasner, Silveira e Kruszon-Moran (1992) e Gilbert e Standford (2000) ressaltaram a importância da infecção sistêmica pós-natal na toxoplasmose ocular. Além disso, a alta incidência da infecção pós-natal documentada no sul do Brasil sugere que a infecção pós-natal pode ser uma forma comum de transmissão da doença (Glasner; Silveira; Kruszon-Moran, 1992). Outro estudo na mesma região comprovou que $8,3 \%$ dos indivíduos com infecção pós-natal, que não tinham retinocoroidite, apresentaram cicatriz após período de sete anos (Silveira et al., 2001). Gilbert e Standfort (2000) relatam que dois terços dos casos de toxoplasmose ocular do Reino Unido são de origem pós-natal.

A TSPN pode trazer sérias consequências a imunodeprimidos, fetos de mulheres grávidas com sorologia negativa da doença, além de comprometer a visão, levando a danos irreversíveis, principalmente quan- do o nervo óptico e mácula são envolvidos (Lieb et al., 2004).

O diagnóstico da doença sistêmica pós-natal e o reconhecimento da origem da infecção são essenciais para o entendimento dos mecanismos básicos da infecção, principalmente para a proteção dos pacientes de risco, para o planejamento de programas de prevenção e para orientação quanto às consequências terapêuticas (Bosch-Driessen; Rothova, 1999).

O tratamento específico da TOPN consiste no uso de pirimetamina, sulfadiazina e ácido folínico. Quando há intensa reação inflamatória, está indicado o uso de corticosteróides via sistêmica. Assim, é importante o correto diagnóstico da TSPN porque é sabido que a administração de corticosteróides durante a parasitemia (sem medicação específica para toxoplasmose) pode causar acentuada destruição da retina e disseminação descontrolada da infecção (Ronday et al., 1995).

Surtos de TSPN têm sido descritos em vários países (Burnett et al., 1998, Mansur; Jones; Lempert, 1978; Moura et al., 2006). De fato, em relação à epidemiologia, a TSPN tem assumido importante papel em todo o mundo. Isto chama a atenção para a importância do diagnóstico não só do paciente acometido pela TSPN, mas também da investigação da origem da doença sistêmica aguda: quantos foram contaminados, quando ela ocorreu e suas complicações. Luft e Remington (1984) comprovaram que a infecção toxoplásmica aguda em membros de família de pacientes com linfadenopatia causada pelo T.gondii é comum. E que a toxoplasmose pode ser encontrada em grupos ou pessoas infectadas a partir de uma origem comum (Akstein; Wilson; Teutsch, 1982; Gonçalves et al., 1995; Teutsch et al.,1979). Adicionalmente tem sido verificada a presença de toxoplasmose ocular em mais de um irmão em uma mesma família (Pinheiro; Oréfice, 1990; Silveira et al., 1988).

Estudos recentes têm discutido o verdadeiro papel da infecção sistêmica pós-natal na doença ocular. Alguns autores (Bahia-Oliveira et al., 2003; Bowie et al., 1997; Burnett et al., 1998; Ross et al., 2001; Silveira et al., 2001) têm sugerido que a infecção sistêmica de origem pós-natal seja uma importante causa de toxoplasmose ocular.

Oréfice et al. (2009) avaliaram casos com evidências clínicas, sorológicas e epidemiológicas de toxoplasmose ocular pós-natal e episódios de comprometimento ocular como única manifestação da infecção sistêmica em que não havia outras evidências clínicas de TSPN. Pesquisas a respeito deste assunto e com tamanha amostra são escassas na literatura mundial, pois essa doença é de difícil diagnóstico e com casos de diagnósticos frequentemente conflitantes (quadros 1 e 2). 


\section{Quadro 1}

Diagnóstico de toxoplasmose ocular pós-natal (TOPN) segundo diversos autores

\begin{tabular}{llc}
\hline Autor (data de publicação) & $\begin{array}{l}\text { Critérios diagnósticos de } \\
\text { toxoplasmose sistêmica pós-natal }\end{array}$ & $\begin{array}{c}\text { Toxoplasmose } \\
\text { ocular pós-natal } \\
\text { (n) }\end{array}$ \\
\hline Hogan (1958) & DT, Clínica**** & 02 \\
Hogan (1964) & DT, Clínica & 05 \\
Darrell et al. (1964)* & Epidemiologia, DT & 21 \\
Mansur, Jones e Lempert (1978) & IFI (IgG+), FC, Clínica & 01 \\
Michelson et al. (1978) & IFI (IgG+), cistos T.gondii pós-biópsia linfonodo & 01 \\
Glasner, Silveira e Kruszon-Moran & (1992)** & Epidemiologia, IgG+ \\
Silveira et al. (2001)*** & Soroconversão & $21,3 \%$ \\
Oréfice et al. 2009, ARVO & IgG+, IgM+, clínica, gravidez***** & 2 \\
\hline
\end{tabular}

(*) Em $80 \%$ da população de 162 pessoas com sorologia positiva para toxoplasmose, lesão de retinocoroidite foi encontrada em apenas pessoas com mais de 20 anos de idade. Devido ao fato de a retinocoroidite não ter sido encontrada em indivíduos jovens, concluiu-se que as lesões encontradas em indivíduos acima de 20 anos seriam de origem pós-natal;

(**) 99,5\% de 184 casos com toxoplasmose ocular apresentaram IgG+. Em pessoas acima de 13 anos, 21,3\% apresentaram toxoplasmose ocular. "A baixa prevalência em crianças nesta população sugere que a toxoplasmose ocular é sequela de infecção pós- natal";

(***) Entre 109 casos soronegativo para toxoplasmose em 1990, 21 tornaram-se soropositivo em 1997;

(****) Clínica - sintomas sistêmicos como: febre, mal-estar, linfonodos;

(*****) Gravidez refere-se aos casos de mulheres que tiveram toxoplasmose durante a gravidez;

DT - Dye Test; FC = Fixação do complemento; IFI = imunofluorescência indireta; IgG = imunoglobulina G; IgM = imunoglobulina M

\section{Quadro 2}

Presença de imunoglobulina $M$ antiT.gondii e frequência de toxoplasmose ocular pós-natal (TOPN) segundo diversos autores

\begin{tabular}{lcc}
\hline Autor (data de publicação) & Pacientes IgM + (n) & $\begin{array}{c}\text { Pacientes com toxoplasmose } \\
\text { ocular pós-natal (n) }\end{array}$ \\
\hline Leblanc et al. (1985) & 01 & 01 \\
Hausmann e Richard (1991) & 01 & 01 \\
Beniz (1993) & 03 & 03 \\
Melamed (1994) & 01 & 01 \\
Nussenblatt e Belfort (1994) & 02 & 02 \\
Oréfice e Tonelli (1995) & 01 & 01 \\
Ronday et al. (1995) & 08 & 08 \\
Stehling e Oréfice (1996) & 06 & 06 \\
Montoya e Remington (1996)* & 21 & 22 \\
Couvreur e Thulliez (1996) & 49 & 43 \\
Burnett et al. (1998)** & 100 & 20 \\
Holland et al. (1999a)*** & 08 & 10 \\
Chiquet et al. (2000) & 01 & 01 \\
Ross et al.(2001) & 05 & 05 \\
Bosch-Driessen et al. (2002)**** & 10 & 14 \\
Atamaca, Simsek e Batioglu (2004)***** & 05 & 49 \\
Lieb et al. (2004) & 01 & 01 \\
Hassene et al. (2008) & 01 & 01 \\
Siqueira, Jorge e Figeiredo (2007) & 01 & 01 \\
Oréfice et al. 2009, ARVO & 47 & 47 \\
\hline (*) & &
\end{tabular}

(*) Um paciente apresentou IgM negativo, porém IgA e IgE positivos;

(**) Surto com 100 casos TSPN (nem todos os casos do surto apresentaram IgM +. Porém, todos com lesão ocular apresentaram IgM positivo);

(**) Um paciente apresentou IgM negativo. Entretanto, apresentou altos títulos de IgG e clínica (febre, linfonodos);

(****) Diagnóstico TSPN foram presença de IgM e/ou IgA contra o T.gondii. Aumento dos títulos de IgG no soro;

(****)Diagnóstico de TOPN: presença de lesão única na retina na ausência de cicatrizes em nenhum dos olhos e aumento dos títulos de IgG contra o T.gondii no soro; IgA - imunoglobulina A; IgE - imunoglobulina E IgG-Imunoglobulina $\mathrm{G}$ 


\section{Revisão da literatura}

\section{Histórico geral}

Laveran (1900) parece ter sido o primeiro autor a descrever o T. gondii em pardais de Java. Nicolle e Manceaux (1908) identificaram o protozoário T. gondii em um roedor norte-africano, Ctenodactylus gondii. Denominou-o, então, Leishmania gondii. Porém, após captura de outros roedores gondiis no ano seguinte e na mesma área, observou que se tratava de um novo protozoário, sendo então denominado toxoplasma. $\mathrm{Na}$ mesma época, Splendore (1908), no Brasil, identificou o T. gondii em coelhos. Os coelhos morreram por paralisia. Eles foram necropsiados e encontraram-se corpúsculos parasitários císticos.

O oftalmologista Janku (1923) foi considerado o primeiro autor a descrever a toxoplasmose em humanos na cidade de Praga. Ele realizou necropsia em uma criança de 11 meses de idade que foi ao óbito devido a uma doença grave e disseminada caracterizada por hidrocefalia, microftalmia e coloboma de mácula.

No Brasil, Margarino Torres, em 1927, descreveu um microorganismo intracelular encontrado em lesões do sistema nervoso central (SNC), músculo-esquelético e coração de um recém-nascido que foi ao óbito devido à meningoencefalite. Ele considerou as lesões semelhantes às produzidas na toxoplasmose experimental, apesar de ter classificado o parasito como Encephalitozoon Chagasi.

Wolf, Cowen e Paige (1939), nos Estados Unidos, identificaram parasitos nas lesões do SNC de recém-nascido que apresentou encefalomielite grave, convulsões, dificuldade respiratória e retinocoroidite bilateral. Inocularam o material em animais de laboratório experimentalmente e concluíram que se tratava de toxoplasmose.

A tétrade de sinais clínicos da doença congênita (hidrocefalia ou microcefalia, retardo psicomotor, calcificações intracranianas e retinocoroidite) foi evidenciada por Sabin e Feldman (1948).

Os primeiros a relacionarem a doença ocular com a infecção toxoplásmica foram Vail, Strong e Stepheson (1943). Eles informaram seis casos de retinocoroidite em adultos e jovens, nos quais encontraram títulos séricos de anticorpos neutralizantes para toxoplasmose.

Koch et al. (1943) mostraram os achados oftalmológicos em seis casos de encefalomielite toxoplásmica infantil diagnosticada clinicamente. As lesões oculares eram frequentemente focais, bilaterais e múltiplas, sendo a região macular quase sempre envol- vida, embora outras lesões periféricas pudessem coexistir. Eles consideraram as lesões necrotisantes e inflamatórias de retina similares às encontradas no cérebro. Sugeriram que a reticoroidite toxoplásmica deveria ser procurada em crianças com alterações do SNC na primeira infância.

Realizando um teste de neutralização em 211 pacientes para avaliar sua especificidade, Heidelmann (1945) concluiu que reações não específicas poderiam ocorrer em 10 a $14 \%$ dos casos sem evidência clínica de toxoplasmose. Sendo assim, a demonstração de anticorpos neutralizantes deveria ser realizada com cautela no diagnóstico de retinocoroidite congênita; e na ausência desses anticorpos também não excluiriam a possibilidade de infecção.

Foi a partir de 1948 que se iniciaram os primeiros estudos epidemiológicos da toxoplasmose. Sabin e Feldman (1948) desenvolveram o teste do corante ou teste de Sabin-Feldman. Verificaram que o citoplasma do T. gondii tornava-se distorcido e pouco corado após contato com soro imune. Este inibe a coloração do citoplasma do toxoplasma vivo pelo azul de metileno. O teste torna-se positivo no início da infecção, com títulos ascendentes nas fases ativas e diminui posteriormente. Sendo assim, tem valor diagnóstico e indica a evolução da doença.

Frenkel (1949) descreveu as fases da infecção toxoplásmica baseada na patogênese e nas manifestações clínicas da infecção. Segundo o autor, a recorrência da retinocoroidite em pacientes com cicatrizes na fase crônica é atribuída à persistência do toxoplasma em estágio latente nos pseudocistos que, quando rompidos, liberam material antigênico. A retinocoroidite foi considerada o sinal clínico mais frequente na toxoplasmose crônica em pacientes assintomáticos.

Um percentual de $23 \%$ dos casos de uveíte posterior tem como agente etiológico o T.gondii (Busacca; Nobrega; Trapp, 1950).

Foi a partir de Wilder (1952) que uma nova fase se iniciou no estudo da toxoplasmose ocular. Avaliaramse 53 olhos enucleados de pacientes com inflamação ocular e que se apresentavam dolorosos ou cegos ao exame. Foram encontrados toxoplasmas no centro das lesões de retinocoroidite, na parte necrótica.

A oftalmia periódica em cavalos, causada pela Leptospira pomona e pela Leptospira grippotyphosa, foi avaliada por Witmer (1954), que analisou o soro e o humor aquoso pela eletroforese e dosagem de anticorpos nos dois fluidos. Essa investigação revelou a produção local de anticorpos, pois em alguns casos houve maior concentração de anticorpos específicos no humor aquoso em relação ao soro. 
Avaliando o soro e humor aquoso de 67 pacientes (metade com suspeita de toxoplasmose ocular), O'Connor (1957) salientou que 11 delas apresentavam títulos positivos no soro e humor aquoso, enquanto sete exibiam títulos positivos apenas no humor aquoso. Esse fato levou-o a concluir que houve formação de anticorpos intraocular.

Goldman (1957) desenvolveu o teste de imunofluorescência para o T. gondii e, a partir de 1960, a toxoplasmose passou a ser considerada a maior causa de uveíte no mundo.

Desmonts (1966) estabeleceu coeficiente toxoplásmico do humor aquoso, que exprimiria a concentração relativa de anticorpos no humor aquoso em relação ao soro, considerando a quantidade de globulinas totais em cada fluido. Salientou-se que somente o coeficiente de anticorpos acima de um provaria a produção de anticorpos para toxoplasmose.

Comparando o teste de Sabin-Feldman com imunofluorescência indireta (IFI), Camargo (1964) obteve total concordância quanto à positividade, mas observou títulos mais altos de positividade com a IFI, a qual considerou de execução mais fácil, preconizando seu uso no diagnóstico de toxoplasmose.

\section{Histórico da toxoplasmose sistêmica pós-natal}

Darling (1908, citado por Chaves-Caballo, 1970), patologista do Panamá, descreveu um caso de um homem de 20 anos de idade com uma doença aguda caracterizada por febre, cefaléia e rigidez muscular. Exame microscópico do tecido muscular revelou organismos encistados, os quais Darling interpretou como sendo sarcosporidia. Chaves-Caballo (1970) constatou que, na verdade, esse organismo se tratava de T. gondii e preconizou que Darling deveria ter recebido o crédito por ter sido o primeiro a descrever toxoplasmose em um adulto humano.

Os primeiros casos da forma adquirida da doença com comprovação histológica foram notificados por Pinketon e Henderson (1941). Relataram dois casos fatais de uma doença exantemática febril com pneumonite atípica em adultos, tendo sido encontrada grande quantidade de toxoplasmas intracelulares em tecidos de ambos os casos.

Ao examinar uma paciente oligofrênica admitida no hospital, Siim (1950) observou linfonodos axilares e inguinais. Um linfonodo foi excisado e apresentava alterações compatíveis com infecção por T. gondii. Além disso, teste do corante mostrou-se com títulos muito altos.

Wising (1952) foi o primeiro a descrever um caso de toxoplasmose ocular adquirida durante o curso da doença sistêmica. A infecção ocular ocorreu no estágio final de uma doença febril em uma mulher de 31 anos com linfadenopatia generalizada. O soro dessa paciente mostrou aumento importante dos títulos do teste do corante durante o curso da doença e a fixação do complemento comprovou aumento dos títulos mais tardiamente.

Para Hogan (1958), para um diagnóstico conclusivo de infecção toxoplásmica seria necessário o isolamento do protozoário do fluido ou tecido do paciente com doença aguda. Nesse mesmo trabalho, ele descreveu dois casos de toxoplasmose ocular que se desenvolveu com duas semanas e quatro meses, respectivamente após a infecção toxoplásmica sistêmica aguda sintomática.

Posteriormente Hogan (1964) avaliou 240 casos de uveítes de provável origem toxoplásmica, classificando-os, segundo o aspecto clínico, evolução, sorologia e presença ou ausência de calcificações cerebrais, em toxoplasmose congênita e adquirida. Encontrou 40 pacientes com toxoplasmose ocular congênita e cinco com toxoplasmose ocular adquirida; dois casos ocorreram no mesmo tempo que a toxoplasmose aguda sistêmica.

O estudo epidemiológico de Darrell et al. (1964), entre nativos de uma ilha no Pacífico Sul, Moen, objetivou determinar a prevalência de doença retinocoroidiana e a prevalência de anticorpos antiT.gondii na região. Teste do corante positivo foi encontrado em $80 \%$ de 162 pessoas testadas e a porcentagem de testes positivos aumentou com a idade. Altos títulos de 1:1024 foram encontrados em $30 \%$ das pessoas com idade entre 5-9 anos e em $48 \%$ das com idade entre 10-19 anos. Retinocoroidite foi apresentado por $21(11 \%)$ paciente e todos eles tiveram teste do corante com títulos de 1:64 ou maior. Lesões de retinocoroidite não foram constatadas em pessoas com menos de 20 anos, mas houve aumento da frequência nos grupos mais velhos (> 20 anos). Como a retinocoroidite não foi encontrada entre os nativos nas faixas etárias de 5-9 e 10-19 anos, então esses títulos altos não seriam causados por toxoplasmose congênita, e sim originados da infecção toxoplásmica adquirida que ocorreu na infância e adolescência dessas pessoas.

Kean, Kimball e Christensen (1969) realçaram um surto de toxoplasmose adquirida aguda envolvendo cinco estudantes de Medicina, em Nova York, que comeram carne de hambúrguer contaminada. Todos manifestaram cefaléia, mialgia, febre e linfadenopatia. O teste do corante Sabin-Feldman e a fixação do complemento revelou títulos muito altos. Avaliação oftalmológica foi realizada em quatro pacientes e estes não apresentaram lesões de retinocoroidite. 
Em revisão de literatura para tentar esclarecer a frequência da toxoplasmose ocular congênita e adquirida, Perkins (1973) estabeleceu como critérios diagnósticos de toxoplasmose recentemente adquirida: a detecção de altos níveis de anticorpos, principalmente o aumento progressivo dos títulos; a observação do micro-organismo em biópsia de tecidos ou fluidos; e a demonstração da infecção toxoplásmica em animais após a inoculação de extratos de tecidos infectados com o protozoário. Além disso, ressaltou que os casos de retinocoroidite com evidência de sorologia positiva para toxoplasmose devem ser considerados de origem congênita, a menos que haja clara história de sinais e sintomas de toxoplasmose recente. Ele concluiu com esse trabalho que: a infecção subclínica por toxoplasmose é muito comum no mundo e que as manifestações sistêmicas são raras na doença adquirida e, mesmo nesses casos, o envolvimento ocular ocorre em 2 a $3 \%$; as complicações da toxoplasmose sistêmica são mais frequentes quando o SNC é acometido (quando o SNC é comprometido, lesões oculares são encontradas em um quarto dos casos); uveíte como sinal único de toxoplasmose adquirida é muito raro; quase todos os casos de retinocoroidite vistos no Reino Unido são consequentes à infecção congênita; não há evidências convincentes de que uveíte anterior, vasculite retiniana ou coroidite geográfica sejam causados por toxoplasmose; infecção uterina pode ser responsável por aborto, mas toxoplasmose congênita nunca foi confirmada em irmãos; uma mulher com anticorpos circulantes contra T. gondii não terá uma criança com toxoplasmose congênita.

Um surto de toxoplasmose em pessoas que viviam num mesmo domicílio em Nova York foi verificado após ingestão de carne contaminada (Mansur; Jones; Lempert, 1978). O objetivo desse estudo foi demonstrar a capacidade da infecção toxoplásmica aguda em causar infecção em várias pessoas ao mesmo tempo, partindo de uma origem em comum. Seis dos sete pacientes acometidos tiveram altos títulos de anticorpos contra T.gondii, consistentes com infecção recente (títulos de DT e IFI maior que 1:1024 e FC maior que 1:4 são sugestivos de infecção recente). Cinco (83\%) dessas pessoas eram sintomáticas. As manifestações mais comuns foram febre e linfadenomegalia, que se desenvolveram sete a 18 dias após a ingestão da carne supostamente infectada. Um paciente apresentou lesão de retinocoroidite 129 dias após a infecção sistêmica aguda.

Michelson et al. (1978) encontraram um caso de uma mulher de 43 anos na Pensilvânia que desenvolveu toxoplasmose adquirida sistêmica (febre e linfoa- denomegalia). Oito dias após, apresentou embaçamento visual no olho direito. Submetida ao exame oftalmológico, foi evidenciada lesão de coriorretinite no olho direito. A IFI ( $\operatorname{IgG}$ ) para toxoplasmose foi de 1:1024 e cinco dias após chegou a 1:2048. Foi realizada biópsia excisional de linfonodo axilar. O material foi corado pelo Giemsa, onde foram encontrados cistos consistentes com T. gondii. O diagnóstico foi então confirmado pelo isolamento de T. gondii após injeção intraperitoneal em camundongos.

Um surto de toxoplasmose aguda que ocorreu em outubro de 1977 em Atlanta, Geórgia, em pessoas que cuidavam dos estábulos foi avaliado por Teutsch et al. (1979). Trinta e sete pessoas apresentaram toxoplasmose sistêmica adquirida aguda. Entre essas 37 pessoas, o diagnóstico de 36 foi baseado somente na sorologia, como se segue: 30 apresentaram IFI-IgG positivos, com títulos $>$ 1:4096; e 31 apresentaram títulos de IFI-IgM positivos; 25 apresentaram ambos os critérios sorológicos. O diagnóstico de toxoplasmose aguda foi estabelecido por um dos três métodos: presença no soro de títulos de anticorpos antiT.gondii > 1:4096 pelo teste IFI; demonstração de anticorpos específicos antiT.gondii IgM $>1: 16$ pelo teste IFI; ou presença da tríade clínica: febre, cefaléia e linfadenomegalia. Dois de três gatos adultos que viviam nos estábulos tinham positividade para toxoplasmose. Os dados sugerem que oocistos de toxoplasma foram a origem da infecção.

Stagno et al. (1980) documentaram um surto de toxoplasmose com evidência clínica, sorológica e epidemiológica, envolvendo 10 membros de uma mesma família de 30 pessoas no Alabama. O principal paciente acometido apresentou manifestações clínicas incomuns como abscesso cerebral, lesões de retinocoroidite progressivas e múltiplas, tonteira, alterações neurológicas, hepatoesplenomegalia, pneumonite e eosinofilia. Esse paciente de três anos de idade era previamente sadio. A toxoplasmose foi confirmada pela demonstração do micro-organismo no cérebro e fluido cérebro-espinhal e existência de anticorpos antiT.gondii IgG e IgM positivos no soro. Alta taxa de soropositividade para toxoplasmose foi encontrada nas crianças em idade pré-escolar dessa família. De 11 crianças, sete (68\%) eram soropositivo para toxoplasmose; entre as sete, seis tinham títulos indicativos de infecção recente para toxoplasmose. Essas crianças e um adulto manifestaram, ainda, sinais e sintomas de infecção aguda por toxoplasmose. O adulto teve congestão nasal, linfadenopatia cervical, tosse não produtiva. As crianças apresentaram: tosse não produtiva (todas as seis), congestão nasal (cinco), linfadenopatias (cinco), mal-estar (quatro), pneumonite (quatro), leucocitose (três), 
eosinofilia (dois), coriorretinite (dois) e envolvimento do SNC (um). Geofagia foi associada estatisticamente à toxoplasmose aguda entre as crianças. Evidência epidemiológica indicou que o surto foi provavelmente causado pela ingestão de oocistos de fezes de gato. A família possuía uma gata. A sorologia para toxoplasmose (hemaglutinação indireta) na gata salientou títulos positivos. Além disso, foram colhidas amostras no solo do jardim da casa, onde foram encontrados oocistos de T.gondii.

Em 1982, Akstein, Wilson e Teutsch (1982) pesquisaram um surto de toxoplasmose nos Estados Unidos, em Atlanta, Georgia. Estudo epidemiológico realizado pelo Center for Disease Control (CDC) sugeriu que a origem dos oocistos de toxoplasma era de gatos infectados que viviam nos estábulos e que as pessoas foram contaminadas por aspiração dos oocistos ou contágio oral, através das mãos; 37 pessoas ficaram doentes e/ou tiveram evidência sorológica de infecção aguda por toxoplasmose; 36 demonstraram anticorpos antiT.gondii; 30 dos 36 apresentaram títulos de IFI-IgG positivos > 1:4096; e 31 tiveram títulos de IFI positivos para IgM. Somente um paciente foi classificado como caso baseado apenas na síndrome clínica. Todos, exceto dois, eram sintomáticos e 25 tiveram a tríade clínica completa: febre, cefaléia e linfadenopatia. A todos os 37 pacientes foi oferecido exame oftalmológico um ano e quatro anos após o surto, tendo 17 sido examinados um ano após o surto. Todos os 37 pacientes foram aconselhados a procurar seu médico oftalmologista, caso apresentassem qualquer sintoma visual, e contatar os autores para posterior seguimento. Depois de quatro anos, 21 pacientes foram reexaminados pelos autores e quatro por seu oftalmologista. Três indivíduos estavam vivendo fora de Geórgia, mas não relataram sintomas visuais. Após o primeiro ano, nenhum dos 17 exibiu doença ocular. Posteriormente ao reexame quatro anos após o surto, um paciente dos 28 examinados apresentou lesão ocular compatível com toxoplasmose.

Ao acompanhar 36 indivíduos que habitavam uma fazenda no interior de Minas Gerais, Coutinho et al. (1982) encontraram que nove desses pacientes apresentaram a forma glandular da toxoplasmose adquirida sistêmica entre maio e agosto de 1976, bem como títulos de anticorpos antiT.gondii IgG e IgM positivos pelo método IFI. Um total de 12 pessoas foi classificado como indefinido - ou por apresentarem clínica de toxoplasmose aguda, porém com títulos de anticorpos baixos (dois casos), ou por não apresentarem clínica da doença aguda, mas com sorologia consistente de infecção recente (sete casos). Dezessete casos apresentaram positividade para
IgM. São fatores suspeitos da causa do surto: a carne de porco mal-cozida durante um churrasco e o solo ou vegetais contaminados com oocistos.

Benenson et al. (1982) descreveram um surto de toxoplasmose aguda sistêmica que ocorreu no Panamá em 39 de 98 soldados norte-americanos, verificando que os anticorpos IFI antiT.gondii IgM de 28 dos 39 eram acima de 1:64. Testes sorológicos de 59 assintomáticos revelaram anticorpos antiT.gondii $\operatorname{IgM}>1: 64$ em três deles. Identificou-se um total de 31 casos confirmados de toxoplasmose aguda (IgM IFI $>1: 64)$. Além disso, quatro soldados tiveram resultados sorológicos, indicando provável infecção, e 32 dos 35 soldados (91\%) eram sintomáticos. Os sintomas mais frequentes eram febre em $90 \%$ dos casos, calafrios em $87 \%$, cefaléia em $77 \%$, mal-estar em $74 \%$, mialgia em $68 \%$, rigidez de nuca em $35 \%$, dor abdominal em $55 \%$, náuseas e vômitos em $36 \%$, artralgias em $29 \%$ e dor ocular em $26 \%$. Linfadenopatia foi observada em $77 \%$ dos casos e a localização mais acometida foi a cadeia cervical posterior em $58 \%$, axilar em $48 \%$ e anterior em 19\%. Esplenomegalia manifestou-se em um paciente e hepatomegalia em dois. Nenhum teve comprometimento ocular juntamente com a doença aguda. Eles ingeriram água de um riacho e se contaminaram.

Para determinar a ocorrência de T.gondii em familiares de nove pessoas que apresentaram linfadenopatia devido à toxoplasmose sistêmica aguda, Luft e Remington (1984) procederam a um estudo que considerou infecção por toxoplasma sistêmica aguda a presença de anticorpos IgM pelo método duplo-sanduíche Enzyme Linked Immuno Sorbent Assay (ELISA). Em cinco das nove famílias estudadas, pelo menos mais de um membro de cada família tiveram evidência sorológica de infecção aguda recente por T. gondii. Em três das cinco famílias, os títulos de antiIgG e IgM para T. gondii em vários membros que tiveram evidência sorológica de aquisição de infecção recente eram similares, independentemente se a linfoadenopatia estava presente ou não. Um total de 20 pessoas apresentou IgM positiva. Em quatro das cinco famílias nos quais múltiplas pessoas foram infectadas, havia gatos; em duas, membros ingeriram leite de cabra não-pasteurizado antes da infecção; em uma verificou-se ingestão de carne de cordeiro mal passada duas semanas antes de sintomas sistêmicos de febre e mal-estar. Concluiu-se que surtos de infecção por toxoplasma ocorrem frequentemente entre membros da mesma família e com a origem da infecção em comum. E que a resposta humoral não se altera com as várias formas de apresentação clínica da doença sistêmica.

Mulher francesa de 28 anos e grávida com cinco meses de gestação apresentou linfonodos 
submaxilares. O teste do corante foi positivo e anticorpos antiT.gondii IFI IgM positivos. A criança nasceu com sinais de toxoplasmose congênita como calcificações cerebrais, hepatoesplenomegalia, microftalmia e cultura de placenta positiva para toxoplasmose. Aos seis anos de idade, a criança teve lesões de retinocoroidite. A mãe, cinco anos após a doença sistêmica, apresentou lesão de retinocoroidite no olho direito (Leblanc et al., 1985).

A ocorrência de toxoplasmose ocular em 112 famílias na cidade de Erechim, Rio Grande do Sul, Brasil, foi analisado por Silveira et al. (1988). Todos os pacientes tiveram achados sorológicos para toxoplasmose, quadro clínico típico de toxoplasmose ocular com retinocoroidite necrosante frequentemente associada a lesões satélites e exclusão de outras causas de retinocoroidite focal, como sífilis e tuberculose.

Vários modelos familiares de toxoplasmose ocular foram observados, como acometimento da mãe e uma criança em nove famílias; a mãe e duas crianças em uma família; a mãe e três crianças em quatro famílias; a mãe e quatro crianças em uma família; a mãe e seis crianças em uma família; e a mãe e oito crianças em uma família. Toxoplasmose ocular estava presente também em dois irmãos de 60 famílias, três irmãos em 18 famílias, quatro irmãos em seis famílias, cinco irmãos em três famílias e seis irmãos em quatro famílias. Em todas essas famílias não havia gêmeos. O quadro clínico típico de toxoplasmose ocular foi também observado em três sucessivas gerações de mulheres em uma das famílias.

Um levantamento de 100 crianças de 10 a 15 anos de idade numa escola pública em Erechim mostrou que somente duas delas não tinham no soro anticorpos para toxoplasmose ( $98 \%$ de soropositividade). Muitas também tinham anticorpos IgM no soro contra o parasito, sugerindo infecção adquirida recentemente (Silveira, 1988).

Rehder et al. (1988) comentaram um caso de um paciente com acquired immunodeficiency syndrome (Aids) que desenvolveu iridociclite aguda unilateral de origem toxoplásmica. Anticorpo antiT.gondii IgG no soro foi de 1:8000 e IgM negativa. O paciente faleceu um mês após e o exame anatomopatológico revelou a presença de cistos de Toxoplasma gondii no estroma da íris e ausência de cistos na retina.

Um paciente de 31 anos de idade com história de deterioração da acuidade visual bilateral em uma semana foi avaliado por Hausmann e Richard (1991). O olho direito, à fundoscopia, exibia oclusão de veia central da retina; e o olho esquerdo, coroidite disseminada. Os autores consideraram o diagnóstico de toxoplasmose adquirida, porque o paciente apresentou soroconversão (três anos antes a IFI IgG e IgM para toxoplasmose era negativa). Durante o quadro oftalmológico, a IFI para toxoplasmose foi de 1:2046 e anticorpos antiT.gondii IgM 1:20. Além disso, outras doenças infecto-contagiosas foram descartadas, como tuberculose, sífilis e citomegalovírus; e houve boa resposta ao tratamento específico para toxoplasmose.

Devido à alta frequência da toxoplasmose ocular e a ocorrência em vários irmãos em Erechim, Rio Grande do Sul, Brasil, Glasner, Silveira e KruszonMoran (1992) realizaram estudo para compreender melhor a epidemiologia da toxoplasmose naquela região. Participaram da pesquisa 1.042 pacientes, tendo $184(17,7 \%)$ apresentado toxoplasmose ocular. Entre os que tiveram toxoplasmose ocular, $183(99,5 \%)$ tinham anticorpos antiT-gondii IgG, comparados com 140 de 181 pacientes-controle $(77,4 \% ; \mathrm{p}<0,001)$. A prevalência da toxoplasmose ocular foi de $0,9 \%$ entre as idades de um a oito anos, $4,3 \%$ entre nove e 12 anos, $14,3 \%$ entre 13 e 16 anos e $21,3 \%$ naqueles com 13 anos ou mais. A prevalência da toxoplasmose ocular nessa população foi 30 vezes mais alta que em qualquer outro lugar no mundo. A infecção congênita é uma improvável explicação para essa alta prevalência, porque, comparada com a prevalência da doença ocular em adultos (mais de $20 \%$ ), a infecção congênita por T. gondii é provavelmente incomum nessa população. Além disso, a toxoplasmose congênita sistêmica clinicamente reconhecível tem sido pouco observada pelos médicos pediatras em Erechim. E menos de $1 \%$ de sangue coletado do cordão umbilical no hospital de Erechim teve sorologia IgM positiva para toxoplasmose em 1990. A baixa quantidade de retinocoroidite verificada em crianças menores de nove anos não é consistente com infecção congênita. Apesar da frequência não ter sido determinada nesse estudo, a ocorrência de lesão ocular em irmãos, em algumas famílias nessa região, não pode ser consequente à sequela de infecção congênita.

A baixa prevalência da doença ocular em crianças mais novas sugere que, nos pacientes dessa cidade, a toxoplasmose ocular é sequela de infecção pós-natal, e não de infecção congênita.

Beniz (1993) destacou três casos de toxoplasmose ocular adquirida. Dois pacientes apresentaram sintomatologia da infecção toxoplásmica sistêmica anteriormente à doença ocular, lesões de retinocoroidite solitárias em atividade e anticorpos antiT.gondii $\operatorname{IgG}$ e IgM positivos. Um indivíduo não tinha sintomas sistêmicos e, além disso, à fundoscopia, havia uma lesão de 
retinocoroidite cicatrizada no mesmo olho em que a lesão de retinocoroidite estava em atividade. Porém, os exames laboratoriais confirmaram a infecção toxoplásmica sistêmica: IgM positiva pelo método ELISA e IFI IgG positiva. Sugeriu-se que, no paciente em que havia uma lesão cicatrizada, esta seria de outra etiologia.

O envolvimento ocular na toxoplasmose avaliado por Rothova (1993) e permitiu-lhe concluir que o diagnóstico de toxoplasmose ocular durante a infecção adquirida aguda pode ser difícil e que, apesar desse diagnóstico ser principalmente clínico, no caso da toxoplasmose sistêmica adquirida aguda a sorologia seria indispensável. Nesse caso, os títulos de anticorpos seriam frequentemente altos. E, para um diagnóstico conclusivo de toxoplasmose ativa, seria necessário o isolamento de T.gondii de fluidos corporais ou tecidos durante o curso da doença aguda, o que seria muito difícil.

Melamed (1994) descreveu um caso de toxoplasmose ocular adquirida de aparecimento tardio. Uma mulher de 39 anos apresentou "floaters", baixa da acuidade visual no olho esquerdo. À fundoscopia, foi evidenciada lesão de retinocoroidite em atividade próxima ao disco óptico. Baseado na presença de anticorpos antitoxoplasma, após serem afastadas outras causas de doenças infecciosas, história clínica, história pregressa e tratamento para toxoplasmose bem-sucedido, foi diagnosticada toxoplasmose ocular. A paciente refere história pregressa de infecção toxoplásmica sistêmica 13 anos antes, no último trimestre de gravidez. O bebê nasceu prematuro, com hepatoesplenomegalia, icterícia sendo diagnosticada, portanto, toxoplasmose congênita. O bebê apresentou, à fundoscopia, numerosas cicatrizes de retinocoroidite, hidrocefalia, calcificações cerebrais à tomografia computadorizada. Anticorpos antitoxoplasma gondii foram positivos. $\mathrm{O}$ autor concluiu então tratar-se de toxoplasmose ocular adquirida de aparecimento tardio.

Dois casos de toxoplasmose ocular adquirida foram abordados por Nussenblatt e Belfort (1994). Um deles, de 20 anos, apresentou febre, linfadenomegalia e perda de peso. Quatro meses após, baixa da acuidade visual no olho direito (OD) e lesão de retinocoroidite em atividade nesse olho. Anticorpos antiT.gondii IgG e IgM foram positivos. Outro paciente, de dois anos de idade, manifestou febre e linfadenopatia, anticorpos antiT.gondii IgG e IgM positivos. Fundoscopia sem alterações. Oito anos após, exibiu cicatriz macular no olho esquerdo (OE) e anticorpos IgG positivo e IgM negativo para toxoplasmose.

O estudo de Gonçalves et al. (1995) identificou três casos de comprometimento ocular por toxoplasmose adquirida um mês após a doença sistêmica, em membros da mesma família. Os pacientes apresentaram linfadenomegalia cervical, febre, mialgia e hiporexia. Exames sorológicos revelaram anticorpos (método ELISA) IgG e IgM para T.gondii positivos. Dois indivíduos tiveram envolvimento bilateral. Um manifestou neurite num olho e retinocoroidite no outro olho. $\mathrm{O}$ envolvimento dos três pacientes sugere uma fonte comum de infecção.

Um caso de uveíte anterior granulomatosa sem retinocoroidite em um paciente de 21 anos foi avaliado por Oréfice e Tonelli (1995). O paciente teve cefaléia, febre e linfadenomegalia cervical bilateral e 14 dias depois baixa da acuidade visual no olho direito. Foram excluídas outras doenças infecciosas e a sorologia para toxoplasmose um mês após demonstrou IFI IgG e IgM positivas para Toxoplasma gondii. O exame foi repetido e confirmado em outro laboratório.

Ronday et al. (1995) relataram oito casos de retinocoroidite focal presumidamente causada por toxoplasmose adquirida. Os pacientes foram submetidos a exame oftalmológico, sorologia para toxoplasmose e vírus e determinação da produção de anticorpos antiT.gondii IgG no aquoso por meio do coeficiente de Witmer-Desmonts. Um coeficiente acima de três foi considerado positivo. O diagnóstico de toxoplasmose ocular pós-natal foi baseado nos achados clínicos, ou seja: presença de retinocoroidite focal sem cicatrizes pré-existentes e a existência de anticorpos antiT.gondii $\operatorname{IgM}(\mathrm{em}$ todos os oito pacientes), em combinação com a soroconversão, precedendo as queixas oculares (um de oito pacientes); aumento dos títulos de anticorpos antiT.gondii IgG de quatro vezes no soro por um período de três semanas (um paciente); altos níveis de anticorpos antiT.gondii $\operatorname{IgG}(>1024$, em sete de oito pacientes); ou a produção de anticorpos contra $\mathrm{T}$. gondii intraocular cinco de oito pacientes). A conclusão é que a retinocoroidite unilateral e focal deve servir de alerta para os clínicos considerarem a toxoplasmose ocular adquirida no diagnóstico diferencial de outras causas de retinocoroidites; e que, também, se deve ter cautela na prescrição de corticosteróides para esses pacientes.

Os seis pacientes avaliados por Stehling e Oréfice (1996) tinham toxoplasmose adquirida sistêmica seguida por comprometimento ocular com intervalo entre a doença sistêmica e doença ocular variável (intervalo de latência). Apresentavam também sorologia para toxoplasmose positiva: IgG e IgM (ELISA e/ou IFI). Outras causas de infecção sistêmica como sífilis, tuberculose, mononucleose foram afastadas: 
No caso 1, uma paciente com toxoplasmose subclínica durante a gravidez e que após seis anos apresentou lesão de retinocoroidite em atividade no OE. O filho nasceu com quadro típico de toxoplasmose ocular congênita.

No caso 2, havia sintomas sistêmicos e, após 15 meses, retinocoroidite no $\mathrm{OE}$ recidivada por duas vezes. Após cinco anos da doença sistêmica, verificou-se lesão de retinocoroidite no OD.

No caso 3, um paciente exibiu lesão de retinocoroidite no OD sete dias após a infecção sistêmica. Adicionalmente, seu pai possuía infecção sistêmica, mas sem comprometimento ocular.

Já o caso 4 manifestou toxoplasmose adquirida subclínica, com lesão ocular. A irmã dessa paciente teve toxoplasmose sistêmica durante a gravidez, cujo recémnascido teve toxoplasmose congênita com lesão ocular bilateral. O noivo da paciente com lesão ocular aguda também apresentou infecção toxoplásmica aguda, porém sem alteração ocular.

No caso 5 havia lesão de retinocoroidite bilateral, com recidivas e intervalo entre a doença sistêmica e ocular de seis anos no OD e nove no OE.

O caso 6 era de toxoplasmose ocular bilateral aguda juntamente com a doença sistêmica.

Montoya e Remington (1996) analisaram 22 casos de pacientes com retinocoroidite por toxoplasmose aguda baseados nos achados clínicos e nos seguintes resultados sorológicos positivos (95,5\% teste de SabinFeldman; 95,5\% ELISA anticorpos antiT. gondii IgM; 90,9\% ELISA anticorpos antiT. gondii IgA; 77,3\% ELISA anticorpos antiT. gondii IgE; 95,5\% ISAGA anticorpos antiT.gondii IgE; e 86,4\% teste AC-HS - teste diferencial de aglutinação - no qual se comparam os títulos de taquizoítos fixados com formalina-antígenos HS com os taquizoítos fixados com acetona ou metanolantígenos AC). Um total de 21 pacientes apresentou IgM. Em um paciente a IgM foi negativa, porém, com IgA, IgE, teste aglutinação e AC-HS positivos. A detecção de anticorpos antiT.gondii IgA e IgE ou o modelo agudo do teste AC-HS foram particularmente de grande ajuda no diagnóstico de pacientes, nos quais os títulos de anticorpos antiT.gondii ELISA eram negativos ou fracamente positivos. Esses exames sorológicos são de valia no diagnóstico de infecção aguda, pois a presença de IgM somente não faz diagnóstico de infecção aguda.

Num período de 13 anos, Couvreur e Thulliez (1996) estudaram 49 casos de toxoplasmose adquirida complicada com envolvimento ocular e/ou neurológico ou envolvimento meníngeo. Eles encontraram 43 casos de lesão ocular, três de meningoencefalite (um caso era associado à retinocoroidite), um de meningite com uveíte, um de poliradicoloneurite e um de paralisia facial. O diagnóstico de doença toxoplásmica adquirida recente foi baseado nos sinais clínicos e/ou sorológicos (presença de anticorpos antiT.gondii IgM positivos) da infecção recente. Todos os casos eram imunocompetentes.

Aumento súbito de casos de toxoplasmose aguda sorologicamente diagnosticados foram verificados por Bowie et al. (1997), na província de Greater Victoria, em março de 1995. Foram definidas 100 pessoas como casos agudos de toxoplasmose. Desses, 94 residiam em Greater Victoria e seis haviam visitado a região; 19 tiveram retinite, 51 linfadenopatia, quatro com sintomas consistentes com toxoplasmose, sete com outros sintomas, 18 sem sintomas e um não deu nenhuma informação. De 3.812 grávidas, 36 que estiveram grávidas recentemente foram consideradas casos. Os casos foram encontrados somente naquela região. Mapeamento dos eventos, das mulheres selecionadas e de ambos os estudos caso-controle mostrou significante associação entre infecção aguda e residência na área onde havia distribuição de um reservatório de água para Greater Victoria.

Burnett et al. (1998) relataram casos de toxoplasmose adquirida devido à contaminação de um reservatório de água na ilha Victoria, British Columbia, Canadá. Desses 100 pacientes, 20 (21 olhos) apresentaram retinocoroidite toxoplásmica adquirida. Os casos foram definidos como pacientes aqueles com achados sorológicos sugestivos de toxoplasmose adquirida (anticorpos antiT.gondii IgM e IgG positivos) e evidência de envolvimento retiniano. Todos os pacientes foram entrevistados para identificar fatores de risco, sinais e sintomas de toxoplasmose.

Com o objetivo de identificar a frequência da infecção recentemente adquirida versus infecção sistêmica crônica por T. gondii em pacientes com toxoplasmose ocular, Ongkosuwito et al. (1999) avaliaram soro de 22 casos com toxoplasmose ocular primária (lesão de retinocoroidite única, sem cicatrizes) e 42 casos com toxoplasmose ocular recorrente, que foram testados quanto à presença de antiTgondii IgM, IgG e IgA e comparados com amostras de 24 outras causas de uveíte. Eles consideraram como critérios diagnósticos da fase aguda da toxoplasmose sistêmica: presença de antiT.gondii IgM no soro, aumento dos títulos de antiT.gondii IgG quatro vezes o valor inicial ou soroconversão. Determinação de antiT.gondii IgA no soro foi usado como diagnóstico adicional de infecção adquirida recente, especialmente em neonatos; $50 \%$ dos casos com TOP estavam na fase 
aguda da infecção sistêmica e em $2 \%$ dos casos com toxoplasmose ocular recorrente.

As recorrências de infecção ocular nos pacientes com toxoplasmose adquirida pós-natal foram investigadas por Bosch-Driessen e Rothova (1999), sendo encontradas em $57 \%$ de 14 casos. Eles consideraram como pacientes em fase aguda da toxoplasmose sistêmica: existência de anticorpos específicos IgM ou IgA no soro; aumento no soro de anticorpos IgG de quatro vezes dentro de um mês após o exame inicial; níveis de anticorpos IgG no soro acima de 1:4096; ou a combinação desses fatores.

No estudo de Holland et al. (1999a), 10 pacientes com toxoplasmose ocular adquirida apresentaram inflamação intraocular na ausência de retinocoroidite. Evidências sugestivas de infecção recente incluíam testes sorológicos (presença de anticorpos antiT. gondii IgM ou títulos IgG muito elevados) ou sinais e sintomas clínicos de toxoplasmose sistêmica (linfadenopatia, mal-estar, febre, faringite, ausência de outras causas identificáveis de doenças infecciosas, história de ingestão de carne mal cozida ou residência em área endêmica no Brasil) ou ambos, evidência sorológica e clínica. Oito pacientes tinham IgM positiva. Um paciente que apresentou IgM negativa teve sintomatológica típica de infecção toxoplásmica pós-natal e títulos de anticorpos IgG muito altos. O outro caso apresentou história de ingestão de carne mal cozida.

Chiquet et al. (2000) acompanharam um caso de uma paciente de 43 anos imunodeprimida devido a um transplante hepático e que apresentou, após três semanas, baixa da acuidade visual em olho esquerdo. A sorologia do doador do órgão era positiva para Toxoplasma gondii. A paciente transplantada, anteriormente ao transplante, apresentava IgG antiT.gondii negativa. Foram, então, após baixa da acuidade visual, realizados novos exames sorológicos e a paciente exibiu positividade para IgG e IgM antiT.gondii (soroconversão). Realizada a reação em cadeia da polimerase (PCR) no humor aquoso esta confirmou a infecção toxoplásmica.

Tentando esclarecer se a toxoplasmose ocular seria causada pela infecção adquirida ou congênita, Gilbert e Stanford (2000) concluíram que a evidência de retinite na ausência de cicatrizes de retinocoroidite prévias em adolescentes ou adultos é consistente com a infecção pós-natal. Sinais de toxoplasmose aguda, como linfadenopatia, aumentam a probabilidade de infecção pós-natal. Quanto aos achados sorológicos, é evidência de infecção pós-natal a detecção de anticorpo antiT.gondii IgM em adultos, o que não afasta, porém, a infecção pré-natal.
Gómez-Marin et al. (2000) estudaram a frequência de anticorpos antiT.gondii IgM, IgA e IgE em 28 pacientes colombianos com toxoplasmose ocular aguda e crônica. Constataram que $10 \%$ dos indivíduos com o primeiro episódio de toxoplasmose ocular eram devidos à infecção adquirida recente, ou seja, presença simultânea de IgM, IgA e IgE. Foram encontrados oito casos com títulos de anticorpos IgM antiT.gondii positivos.

Ross et al. (2001) avaliaram cinco casos de toxoplasmose ocular adquirida em pacientes com história pregressa de ingestão de carne mal passada de veado ou manipulação de carne crua em homens previamente saudáveis. Todos os pacientes tiveram história de doença pregressa à infecção ocular semelhante à gripe. Além disso, tinham títulos de anticorpos antiT.gondii IgG e IgM elevados.

No intuito de entender melhor a história natural da toxoplasmose, Silveira et al. (2001) fizeram exame oftalmológico (oftalmoscopia indireta em todos pacientes e retinografia em alguns casos) e testes sorológicos para T.gondii em 383 pacientes no Sul do Brasil em 1990 e repetiram os mesmos testes em 1997 . Desses 383 pacientes, 109 eram soronegativo para toxoplasmose em 1990 e, em 1997, 21 (19,3\%) tornaram-se soropositivo e dois $(1,5 \%$ dos pacientes soronegativo e $9,5 \%$ dos que soro converteram) tiveram toxoplasmose ocular. De 131 pacientes soropositivos sem lesão ocular em 1990, 11 tiveram lesão ocular típica de toxoplasmose em 1997; 13 tinham lesões retinianas hiperpigmentadas atípicas na retina em 1990 e em 1997, três apresentaram lesão típica para toxoplasmose. Eles concluíram que a infecção toxoplásmica adquirida sistêmica pode levar à doença ocular tardia.

O estudo retrospectivo de Bosch-Driessen et al. (2002) com uma amostra de 154 pacientes com toxoplasmose ocular ativa enfatizou lesões primárias de retina em $28 \%$ dos casos e a combinação de lesões ativas e cicatrizes antigas em $72 \%$ deles. Pacientes com toxoplasmose ocular primária eram mais velhos que aqueles com a combinação de lesões ativas e cicatrizes antigas $(\mathrm{p}<0,001)$ e estes apresentavam intensa reação inflamatória. O percentual de 82\% (14 casos) com características sorológicas da fase aguda da doença sistêmica (presença de anticorpos antiT.gondii IgM e ou IgA) tinham lesões primárias, comparados com $23 \%$ dos pacientes com toxoplasmose ocular na fase crônica da infecção sistêmica $(p<0,001)$. Somaram-se 10 casos com IgM positiva. Extensas lesões retinianas foram mais frequentemente observadas durante a fase aguda da infecção sistêmica $(\mathrm{p}=0,02)$ e em pacientes com toxoplasmose ocular primária $(\mathrm{p}<0,04)$. Eles concluí- 
ram que as recorrências em $79 \%$ dos pacientes podem ocorrer anos após e que acometem mais frequentemente o olho afetado previamente. Os fatores de risco para perda visual foram: infecção congênita, toxoplasmose ocular durante a fase aguda da infecção sistêmica, localização central e extensão das lesões e administração de corticosteróides sem a cobertura das drogas antiparasitárias.

Entre outubro de 1995 e março de 2002, Carme et al. (2002) descreveram 16 casos de toxoplasmose adquirida em pacientes imunocompetentes na Guiana Francesa. Ressaltaram que 12 pacientes tiveram soroconversão recente. Quanto aos outros quatro, a IgM associada à $\operatorname{IgA}$ ou à baixa avidez de $\mathrm{IgG}$ foi altamente sugestiva de infecção recente. Em todos os episódios, a apresentação clínica foi marcada por sintomas semelhantes aos da síndrome infecciosa, como alteração do estado geral, perda de peso e febre. Em algumas vezes, verificaram-se aumento de enzimas hepáticas (15 pacientes), aumento de linfonodos (nove pacientes) e envolvimento pulmonar (14 pacientes), baço (oito pacientes) e ocular (quatro pacientes). Treze pacientes declararam o consumo de carne de caça duas semanas antes do início dos sintomas. Dois confirmaram o consumo, porém não souberam precisar se foi recente ou não.

Um caso de paciente imunocompetente que apresentou toxoplasmose pulmonar foi notificado por Viegas et al. (2002). O indivíduo apresentou anticorpos antiT.gondii IgG e IgM positivos, com boa resposta ao tratamento específico para toxoplasmose.

Com o objetivo de determinar a soroprevalência de anticorpos antiT.gondii em pacientes com doença ocular na Eslovênia, Logar et al. (2002) avaliaram 413 pacientes com doença ocular, sendo a sorologia positiva para toxoplasmose em 236 (57,1\%). Destes, em 218 $(92,4 \%)$ a IgG foi positiva; 202 tinham baixos títulos de 1:16 - 1:256; e $16(7,3 \%)$ demonstraram títulos de 1:1024 - 1:6384. Em 18 dos 236 (7,6\%), a idade dos pacientes variou entre 20 e 74 anos e estes apresentaram anticorpos IgM positivos. Onze desses 18 pacientes também apresentaram anticorpos antiT.gondii IgA positivos. Pôde-se concluir que toxoplasmose aguda foi detectada em 18 de 413 pacientes. E que coriorretinite em infecção toxoplásmica sistêmica aguda não associada a outras cicatrizes provavelmente reflete infecção adquirida pósnatal.

Ramchandani et al. (2002) identificaram um caso de uma paciente que teve toxoplasmose ocular adquirida durante a gravidez. Ela estava com nove semanas de gestação e baixa da acuidade visual no olho esquerdo. À fundoscopia, apresentou lesão de retinocoroidite em ati- vidade, superiormente à fóvea. Foi realizado o teste do corante para toxoplasmose, que revelou título de 1/4096 (2000 UI/mL), anticorpo antiT.gondii IgM (ELISA) positivo. A avidez de IgG para toxoplasmose demonstrou que a infecção era aguda. A PCR para T.gondii em sangue periférico da grávida foi negativa.

Em revisão sobre a imunopatogonêse na toxoplasmose, Hegab \& Al-Mutawa (2003), dando ênfase aos problemas oculares devido à alta morbidade da doença, definiram para o diagnóstico de toxoplasmose adquirida a presença de anticorpos antiIgM no soro ou o aumento dos títulos de $\mathrm{IgG}$ quatro vezes.

Foram revistos prontuários de 189 pacientes (243 olhos) com toxoplasmose ocular, examinados entre 1972 e 1999 (Atamaca; Simsek; Batioglu, 2004). Realizou-se retinografia e, em alguns pacientes, procedeu-se à angiofluoresceinografia e indocianina verde. Do total, $140(74 \%)$ tiveram toxoplasmose ocular congênita e 49 (26\%) toxoplasmose ocular adquirida. Cinco pacientes apresentaram IgM positiva. Os critérios usados para diagnóstico de toxoplasmose ocular adquirida foram lesão retiniana única sem qualquer cicatriz nos olhos e, adicionalmente, a constatação de anticorpo antiT.gondii $\operatorname{IgM}$ no soro e o aumento dos títulos de anticorpo antiT.gondii IgG quatro vezes a titulação inicial.

Lieb et al. (2004) descreveram uma paciente com retinite toxoplásmica adquirida aguda semelhante à maculopatia idiopática aguda. Uma mulher de 39 anos de idade apresentou baixa da acuidade visual no olho direito em janeiro de 2003. A família declarou o hábito de comer carne de veado caçado pelo marido. A paciente teve história pregressa de doença semelhante a resfriado comum em dezembro de 2002, que melhorou várias semanas após. Além disso, detectou linfonodo occipital por três dias. Exames laboratoriais anticorpos antiT.gondii IgG e IgM foram positivos.

A distinção sorológica entre infecção congênita e adquirida na doença ocular toxoplásmica mostra que antiT.gondii $\mathrm{IgG}$ com baixos títulos provavelmente se deve à reativação da doença congênita. Títulos altos de antiT.gondii IgM são verificados em pacientes com doença adquirida aguda; se negativos, indicam a reativação da doença congênita. Em relação à avidez de $\mathrm{IgG}$, caso esteja alta, exclui-se infecção recente de menos de 3-4 meses, porém a baixa avidez pode persistir por até três meses após a primo-infecção. A produção de anticorpos antiT.gondii intraocular, determinada pelo cálculo do coeficiente de Goldmann-Wittmer ou WittmerDesmonts, confirma o diagnóstico de toxoplasmose ocular, constituindo-se em uma prova indireta da existência 
do parasito dentro do olho. A PCR em vítreo ou humor aquoso é indicada em pacientes com lesões retinianas atípicas ou resposta inadequada à terapia (Montoya; Liesenfeld, 2004).

A revisão de Bonfioli e Oréfice (2005) sobre toxoplasmose destaca que a infecção adquirida recente se caracteriza pelo aumento de anticorpos antiT.gondii IgG e baixa avidez de IgG, além do aumento dos anticorpos contra T.gondii IgM, IgA e IgE.

Numa pesquisa em Erechim, Rio Grande do Sul, Brasil, Jones, Alexander e Roberts (2006) procuraram determinar os fatores de risco para toxoplasmose aguda naquela área. O questionário foi preenchido por 130 pessoas, informando sobre seus hábitos alimentares relativos a fatores de risco para a doença. Foram tidos como casos de infecção recente por T. gondii pacientes com teste positivo para anticorpos antiT.gondii IgG e IgM. Concluiu-se que cuidados devem ser tomados em relação à manipulação com o solo, ingestão de água e alimentos, para reduzir-se o risco de infecção pelo T.gondii.

Exames sorológicos para toxoplasmose foram feitos por Palanisamy et al. (2006) em 249 indivíduos durante o surto na cidade de Coimbatore, Índia, em 2004. Em todos os casos houve baixa da acuidade visual. Exame oftalmológico foi consistente com toxoplasmose ocular. Testes sorológicos como anticorpos antiT.gondii, ELISA, IgG e IgM foram realizados, obtendo-se altos títulos de anticorpos IgM e IgG em 178 ocorrências e quatro casos com apenas IgM. O reservatório de água da cidade pode ter sido a causa da disseminação da infecção sistêmica aguda.

Moura et al. (2006) relataram um surto de toxoplasmose sistêmica aguda que ocorreu na cidade de Santa Isabel do Ivaí, Paraná, Brasil, entre novembro de 2001 e janeiro de 2002. Foram registradas 426 pessoas com anticorpos antiT.gondii IgM e IgG positivos pelo método ELISA. Foi realizado exame oftalmológico em 408 pessoas que apresentaram anticorpos antiT.gondii IgM e IgG positivos em fevereiro de 2002. Destes, $10 \%$ tiveram lesões oculares e somente $4,4 \%$ apresentaram lesão retiniana necrosante. Os autores propuseram que a causa do surto foi um reservatório de água que havia sido contaminado com oocistos de T. gondii eliminados por gatos que viviam naquela área.

Uma paciente de 42 anos com toxoplasmose adquirida foi referida por Graff e Russel (2007). O diagnóstico foi considerado pelo fato de a doença ocular ter sido precedida de sintomas sistêmicos semelhante à gripe. Pesquisa de anticorpos antiT.gondii IgG foi positiva e IgM negativa. Foram avaliadas outras doenças infec- ciosas como sífilis, AIDS, tuberculose, leucemia e linfoma, tendo sido todas negativas.

Hassene et al. (2007) descreveram um caso de um paciente com toxoplasmose adquirida aguda que teve polimiosite e retinocoroidite. O diagnóstico foi confirmado pela sorologia (IFI e técnicas imunoenzimáticas) fortemente positiva para anticorpos antiT. gondii IgG e IgM positivos. A biópsia muscular revelou cistos de $\mathrm{T}$. gondii.

Retinocoroidite toxoplásmica aguda bilateral após terapia com corticosteróides para tratamento da síndrome respiratória por antavírus foi referenciada por Siqueira, Jorge e Figueiredo (2007) em um caso. O paciente apresentou perda visual bilateral dois meses após receber terapia com corticosteróides para tratamento de falência respiratória secundária à síndrome pulmonar por antavírus. Foram realizadas sorologia IgG e IgM antiT.gondii, que se mostraram, respectivamente, $>0,600$ e $>300 \mathrm{UI} / \mathrm{mL}$. O paciente foi tratado com medicação específica para T. gondii, com cicatrização das lesões.

Delair et al. (2008) fizeram um estudo comparando toxoplasmose presumida congênita e adquirida. Concluíram que em casos nos quais a origem da infecção pôde ser determinada, a forma adquirida foi mais frequente que a congênita. Observaram também que os casos de toxoplasmose congênita foram mais graves que os de adquirida.

Palkovacs et al. (2008) relataram um caso de retinite toxoplásmica em um paciente imunodeprimido. Ressaltaram a importância de considerar a biópsia por PAAF (Punção Aspirativa com Agulha Fina) como uma ferramenta diagnóstica em pacientes selecionados com infiltrado retiniano.

Garweg et al. (2008) estudaram as características de recorrência da toxoplasmose ocular em uma população européia. Concluíram que pacientes jovens apresentam um maior risco de desenvolver recorrência que pacientes mais velhos. Mostraram também que na população estudada dois terços dos pacientes com toxoplasmose ocular desenvolveram recorrência.

Holland et al. (2008) também estudaram os padrões de recorrência associados à retinocoroidite por toxoplasmose. Concluíram que o risco de recorrência é influenciado pela idade do paciente, assim como duração da infecção.

Lynch MI, Oréfice F et al. (2008) estudaram a característica clínica de uveíte posterior presumida de toxoplasmose em 64 pacientes de Pernambuco. Concluíram que o principal sintoma encontrado foi redução da acuidade visual, e que alterações no humor vítreo foram observadas em todos os casos estudados. 
Oréfice et al. (2009) escreveram:

\section{Toxoplasmose ocular adquirida em pacientes brasileiros}

Proposta: Avaliar o intervalo entre a infecção documentada de toxoplasmose sistêmica e a primeira detecção de toxoplasmose ocular (TO) em uma população brasileira.

Métodos:Trata-se de uma revisão retrospectiva de prontuários de 2168 pacientes avaliados no Setor de Uveíte do Hospital São Geraldo / HC / UFMG, de abril de 1982 a outubro de 2007. Após uma avaliação completa, 1552 pacientes foram diagnosticados como toxoplasmose ocular presumida e destes, 47 foram considerados de terem adquirido infecção adquirida por toxoplasmose através da demonstração de anticorpos antiT.gondii IgG e IgM positivos. Os seguintes dados foram coletados: apresentação clínica da toxoplasmose sistêmica e intervalo entre doença sistêmica e a primeira detecção de toxoplasmose ocular. Foram avaliados idade e gênero dos pacientes, assim como apresentação clínica da doença ocular no momento da primeira detecção da doença.

Resultados: pacientes com toxoplasmose sistêmica primária documentada apresentaram uma variedade de achados clínicos ao diagnóstico inicial: linfadenopatia $(n=21)$, inespecíficos (febre, mialgia, adinamia, cefaléia, hepatoesplenomegalia; $n=6$ ), pneumonia $(n=1)$, sintomas oculares somente (TO; $n=8)$ e indeterminados $(n=7)$. Os quatro pacientes remanescentes tiveram soroconversão durante a gravidez e foram acompanhados no mesmo serviço pelo primeiro autor. $\mathrm{O}$ intervalo entre os primeiros achados da infecção sistêmica à detecção da TO variou: $0(\mathrm{n}=8)$, 1-90 dias $(n=20), 91$ dias-36 meses $(n=9),>36$ meses $(\mathrm{n}=10)$. A média de idade (desvio padrão) dos pacientes no momento de detecção da TO foi de 34,26 e 15,69 (variação de 6 a 67 anos). A TO apresentou-se como retinocoroidite em 44 pacientes, papilite em 1 paciente e uveíte anterior granulomatosa em um paciente. No paciente remanescente, uma baixa visual associada com o desenvolvimento de membrana epirretiniana foi o único achado ocular identificado no tempo da doença sistêmica.

Conclusão: nesta série de casos de pacientes com toxoplasmose ocular adquirida, demonstramos que TO pode se desenvolver até 23 anos após a infecção sistêmica inicial.

\section{Formas clínicas da toxoplasmose sistêmica pós-natal}

A gravidade da doença e a forma clínica dependem do estado imunológico do hospedeiro, da agressividade das cepas do parasito e do estágio evolutivo (Frenkel, 1985). Pinkerton e Henderson (1941) e Krick e Remington (1989), de acordo com a localização da lesão tecidual causado pelo T. gondii, classificaram a doença em três formas clínicas: toxoplasmose aguda, subaguda ou subclínica e toxoplasmose crônica.

Quando o indivíduo é infectado pela primeira vez, sem imunidade adquirida anterior pelo parasito, o protozoário inicia uma fase de multiplicação rápida (taquizoítos), invasão e destruição celular progressiva, expandindo, assim, o seu parasitismo por via hematogênica e linfática. Essa fase da infecção, fase agu$\mathrm{da}$, ocorre de forma inaparente no hospedeiro humano imunocompetente, originando a toxoplasmose infecção. Quando há sintomas, que geralmente são benignos, origina-se a toxoplasmose doença (Coutinho; Vergara, 2005). Já na fase subaguda, os títulos de anticorpos vão aumentando no soro, sendo mais frequentes na forma congênita da doença. No adulto essa fase é assintomática. A fase crônica ou latente refere-se àquela em que há predomínio da forma de cistos contendo parasitos viáveis em seu interior, nos tecidos do hospedeiro (principalmente no músculo estriado, cardíaco, retina e SNC).

A toxoplasmose sistêmica de origem pós-natal tem como apresentação mais comum a forma assintomática ou subclínica, que corresponde aproximadamente a 70\% dos casos. Quanto à forma sintomática, acontece em $30 \%$ dos casos sob a forma ganglionar, pulmonar, neurológica e ocular (Oréfice; Bahia-Oliveira, 2005). A infecção toxoplásmica aguda durante a gravidez é assintomática na maioria das mulheres (Montoya; Liesenfeld, 2004).

O quadro clínico da infecção sintomática em imunocompetentes seria um quadro autolimitado, benigno e inespecífico de uma doença infecciosa que raramente necessita de tratamento. A mais típica manifestação clínica é a forma ganglionar, caracterizada por linfadenopatia indolor, de localização cervical ou occipital, sem supuração, geralmente bilateral, que regride em algumas semanas, podendo os gânglios permanecer aumentados por quatro a seis semanas. Pode ser acompanhado por sintomas gerais como cefaléia, dor de garganta, febre, mal-estar, suores noturnos, mialgias e exantema máculo-papular. O T.gondii causa 3-7\% das linfadenopatias clinicamente significantes. O diagnóstico diferencial se faz com linfomas, mononucleose infecciosa, doença da arranhadura do gato, sarcoidose, tuber- 
culose, carcinoma metastático e leucemia. O diagnóstico da linfadenopatia de origem toxoplásmica é feito facilmente pela sorologia para toxoplasmose e ou biópsia de linfonodos (Remington, 1974).

Menos frequentemente, miocardite, pneumonite, polimiosite, encefalite e hepatite podem comprometer indivíduos imunocompetentes. A pneumonia é difusa e pode apresentar-se com tosse seca, expectoração escassa, cianose e dispnéia. Associam-se sintomas gerais como febre, cansaço e mal-estar. Petéquias e equimoses acompanham o quadro pulmonar.

A encefalite caracteriza-se por confusão mental, febre, cefaléia e convulsões. No líquor encontram-se discreta pleiocitose mononuclear e aumento de proteínas (Oréfice; Bahia-Oliveira, 2005).

A miocardite apresenta-se com dispnéia, dor torácica, febre, náuseas, alterações no eletrocardiograma, podendo levar à falência cardíaca (Mullan; Henry; Beverly, 1968).

O Toxoplasma gondii pode causar hepatite granulomatosa e, consequentemente, cirrose hepática. Ustun et al. (2004) informaram 68,5\% de toxoplasmose sistêmica aguda (presença de anticorpos antiT.gondii IgG e IgM) em pacientes com diagnóstico de cirrose hepática.

A polimiosite inicia-se com fraqueza muscular proximal e simétrica, elevação de enzimas musculares e alterações eletromiográficas típicas de inflamação aguda (Montoya et al., 1997).

\section{Manifestações oculares}

Lesão de retinocoroidite típica seria uma retinocoroidite focal necrosante acompanhada de reação vítrea, que pode estar associada à lesão cicatrizada satélite, indicativa de ataque recorrente. A retinocoroidite por toxoplasmose pode ser de origem congênita ou pós-natal, como resultado de infecção aguda ou reativação (Montoya; Remington, 1996; Holland, 1999a). Aproximadamente dois terços dos pacientes têm reativações que podem ocorrer nas margens das lesões antigas, no mesmo olho acometido, porém longe do foco primário e no olho adelfo (Oréfice; Bahia-Oliveira, 2005). Bosch-Driessen e Rothova (1999) constataram 57\% de recorrências num período de acompanhamento de 4,6 anos.

A toxoplasmose ocular de origem pós-natal pode ocorrer ao mesmo tempo que a infecção sistêmica, ou seja, concomitantemente (intervalo de latência zero), ou ocorrer após um intervalo de tempo depois da infecção sistêmica (intervalo de latência variável). Melamed (1994) descreveu um caso de toxoplasmose ocular de origem pós-natal que ocorreu 13 anos após a infecção sistêmica. Stehling e Oréfice (1996) relataram seis casos de toxoplasmose ocular de origem pós-natal e intervalo de latência variável, sendo um caso de toxoplasmose ocular simultaneamente (intervalo de latência zero) à doença sistêmica.

A doença ocular pós-natal pode, adicionalmente, apresentar-se como reações inflamatórias como neurite, vitreíte, iridociclite e vasculite, sem a lesão de retinocoroidite. Rehder et al. (1988) destacaram um caso de paciente imunocomprometido que apresentou iridociclite aguda unilateral de origem toxoplásmica sem lesão de retinocoroidite. Oréfice e Tonelli (1995) salientaram um evento de iridociclite granulomatosa em paciente imunocompetente, sem retinocoroidite. No estudo de Holland et al. (1999b), 10 pacientes com toxoplasmose ocular adquirida exibiram inflamação intraocular na ausência de retinocoroidite. Gonçalves et al.(1995) referiram um episódio de toxoplasmose ocular de origem pós-natal, no qual o paciente teve lesão de retinocoroidite em atividade em um olho e neurite e vitreíte no outro olho, sem lesão de retinocoroidite, o que sugere que a inflamação inicial seria causada por parasitos intraoculares ou por reação de hipersensibilidade aos antígenos parasitários (Oréfice; Bahia-Oliveira, 2005).

Complicações como irite granulomatosa, pressão intraocular elevada, vasculite retiniana, oclusões vasculares, descolamento de retina seroso ou regmatogênico podem dificultar o diagnóstico correto da toxoplasmose ocular (Fardeau et al., 2002).

\section{Diagnóstico}

O diagnóstico da infecção pelo T.gondii baseia-se frequentemente nos resultados sorológicos. Investigase a detecção de anticorpos contra o protozoário das classes $\operatorname{Ig} G, \operatorname{Ig} M, \operatorname{Ig} A$ e IgE. No caso dos pacientes imunocomprometidos, o diagnóstico é realizado, quase sempre, pela detecção do DNA do parasito por meio de PCR, isolamento do parasito e histologia.

A fase aguda da toxoplasmose sistêmica caracteriza-se pela presença de anticorpos antiT.gondii IgM no soro; aumento dos títulos de anticorpos antiT.gondii IgG de quatro vezes no soro; ou soroconversão (Ongkosuwito et al., 1999). A determinação de anticorpos antiT.gondii IgA é um teste adicional, principalmente em neonatos. Bosch-Driessen et al. (2002) consideram como fase aguda da infecção, a existência de anticorpos antiT.gondii IgM e/ou IgA. Beneson et al. (1982) definem para diagnóstico de toxoplasmose aguda sistêmica a verificação 
de anticorpos antiT.gondii IgM no soro. Na fase crônica, encontram-se anticorpos $\mathrm{IgG}$ em baixos níveis e ausência de IgM. O diagnóstico laboratorial também pode ser utilizado no caso da toxoplasmose ocular.

\section{Anticorpos antiT.gondii IgG}

Os anticorpos antiT.gondii IgG são identificados pelo teste do corante Sabin-Feldman, FI, ELISA, teste de atividade de $\operatorname{IgG}$ e teste da reação de hemaglutinação e diferencial de aglutinação. Eles estão presentes entre 1-2 semanas após a infecção, atingem o pico em um ou dois meses e persistem detectáveis por toda a vida do paciente.

\section{Anticorpos antiT.gondii IgM}

Os testes de IgM têm sido usados para o diagnóstico da infecção aguda. Esse anticorpo não atravessa a placenta e, por isso, quando encontrado no sangue de neonatos, é de origem fetal. Trata-se de um teste no qual os resultados têm que ser analisados com cautela, porque os títulos podem persistir por anos e a confiabilidade dos testes existentes variam consideravelmente. Os métodos utilizados para detecção de IgM são IFI, ELISA, ISAGA. Os anticorpos IgM surgem na segunda semana após a primo-infecção, atingindo níveis máximos no fim do primeiro mês, e desaparecem em 6 a doze meses. Conclui-se portanto que, após o desaparecimento dos anticorpos IgM, o indivíduo encontra-se na fase crônica ou latente da infecção pelo toxoplasma, visto que apenas os anticorpos IgG estarão presentes nessa fase. Já a persistência de IgM na ausência de IGA indica imunidade estabilizada.

\section{Anticorpos antiT. gondii IgA}

Os anticorpos IGA são detectados no soro de adultos agudamente infectados e de recém-nascidos congenitamente infectados pelos métodos ELISA e ISAGA. São detectados durante a primeira semana de infecção, atingem níveis máximos em dois meses e os níveis caem em seguida. Podem persistir por até um ano e, por isso, são de limitado valor no diagnóstico da infecção aguda em adultos.

\section{Diagnóstico da toxoplasmose ocular}

A produção local de anticorpos tem sido usada com sucesso no diagnóstico de toxoplasmose ocular. O coeficiente de Goldman-Witmer demonstra a produção intraocular de anticorpos anti T.gondii. A detecção do DNA do parasita por intermédio da técnica PCR no humor aquoso e corpo vítreo tem demonstrado bons resultados para o diagnóstico de toxoplasmose ocular.

\section{Intervalo de latência}

Em conformidade com a literatura Oréfice et al. (2009) demonstraram que o intervalo de latência pode ser muito variável, dificultando o diagnóstico da TOPN.

Mansur, Jones e Lempert (1978) referenciaram um caso de retinocoroidite 129 dias após a infecção sistêmica. Em outro estudo, Akstein, Wilson e Teutsch (1982) avaliaram um surto de toxoplasmose adquirida que ocorreu em Atlanta, Geórgia. Um paciente desenvolveu retinocoroidite por toxoplasmose quatro anos após o surto. Já Hausmann e Richard (1991) salientaram um caso clínico no qual a paciente teve a doença ocular três anos após a doença adquirida. Beniz (1993) descreveu três casos de TOPN dos quais dois apresentaram doença ocular ao mesmo tempo da doença sistêmica e um caso, dois meses depois. Melamed (1994) publicou um caso clínico de uma paciente que teve lesão de retinocoroidite 13 anos após toxoplasmose sistêmica adquirida durante a gravidez. Stehling e Oréfice (1996) relataram seis casos de toxoplasmose ocular de origem pós-natal e intervalo de latência variável. No Sul do Brasil, foi realizada uma investigação com onze pacientes soropositivos para toxoplasmose sem lesão de retinocoroidite em 1990, que desenvolveram lesão de retinocoroidite sete anos após. Dois que tiveram soroconversão, também exibiram lesão de retinocoroidite em 1997 (Silveira et al. 2001).

O exato momento da infecção adquirida sistêmica é mais claramente estabelecido quando a doença ocular ocorre durante a fase aguda da TOPN, visto que $80 \%$ dos casso de TSPN não manifestaram sintomas. Ademais, não há como saber se o paciente desenvolverá a doença ocular ou quando esta acontecerá. Leblane et al. (1985) afirmam que isso se verifica até 5 anos após a TSPN. Segundo Bosch-Driessen et al. (2002), a doença ocular ocorrendo na fase inativa da doença sistêmica é mais comum e o tempo de latência é muito variável. A TOPN concomitante foi ressaltada também por Wising (1952), Beniz (1993), Stehling e Oréfice (1996), Hogan e Kimura (1964) e Oréfice et al. (2009).

\section{Caso clínico}

Identificação: M.F.R.S., 34 anos, masculino, branco. QD: Gânglios cervicais difusos com febre por trin- 
ta dias em 12/3/2007. Nessa ocasião foi diagnosticada toxoplasmose sistêmica. A sorologia no momento da infecção foi $\operatorname{IgG}$ 1:128, IgM 1:1024.

Em março de 2008 ( $1^{\mathrm{a}}$ crise $)$, o paciente apresentou baixa visual em OD. Neste momento, sorologia para toxoplasmose IgG 297,7UI/ml e IgM 4,34UI/ml, ambos positivos baseados nos valores de referência. Foi então iniciado tratamento clássico para toxoplasmose.

Em 9/4/2008 foi instituído Bactrim F por 4 meses (sic).

Em 10/2/2009 (2 $2^{\mathrm{a}}$ crise):

Em 4/3/2009, momento em que o paciente foi atendido pela primeira vez pelo primeiro autor, ODV 20/50++, OEV 20/20 (ETDRS). À biomicroscopia, OD segmento anterior sem reação inflamatória, corpo vítreo sem células; OE normal. Ao exame fundoscópico (figuras 1 a 9). Foi iniciado tratamento clássico para toxoplasmose. Sorologia anticorpo antiT.gondii IgG positivo e IgM negativo.

Em 18/3/2009 foi realizada a última revisão. ODV 20/25 (ETDRS), OEV 20/20 (ETDRS). Biomicroscopia dos segmentos anterior e posterior inalterados. Ao exame fundoscópico.

Resumo: Intervalo de latência (IL)

"IL: $1^{\mathrm{a}}$ crise: 12 meses (forma sistêmica 03/07, ocular 03/08 OD);"

"IL 2 ${ }^{\mathrm{a}}$ crise: 23 meses (forma sistêmica 03/07, ocular 02/09 OD)."

\section{Tratamento}

\section{Uso oral}

1. Merticorten $20 \mathrm{mg}$ 25 comprimidos 25dias:

* Tomar no café da manhã;

* 2 comprimidos por 7 dias;

* 1 comprimido por 6 dias;

$* 1 / 2$ comprimido por 6 dias;

* $1 / 4$ comprimido por 6 dias e parar.

2. Daraprim $25 \mathrm{mg}$.................. 72 comprimidos.......... 35 dias:

* Tomar 3 comprimidos por dia durante 2 dias;

* 2 comprimidos por dia durante 33 dias;

3. Sulfadiazina $500 \mathrm{mg} . . . . . . . . . . . .280$ comprimidos.... 35 dias:

* Tomar 2 comprimidos de 6 em 6 horas (4 vezes ao dia).

4. Ácido Folínico $15 \mathrm{mg}$........... 35 comprimidos......... 35 dias (manipular):

* Tomar 1 comprimido ao dia por 35 dias.

\section{Comentários}

Na TOPN (Toxoplasmose Ocular Pós-Natal) é sempre prudente lembrar de que se trata de uma entidade com inúmeras características. Portanto, torna-se perigoso, cientificamente, considerar a TOPN como uma entidade morfológica e topográfica típica (Exemplo: retinopatia herpética necrosante??? - figura 10 caso clínico 2).

Na presença da TOPN, deve-se ter o cuidado ao oferecer a oportunidade de se pensar em um diagnóstico diferencial. Como a TOPN se apresenta como uma lesão focal posterior do tipo granulomatosa, há uma série de outras uveítes que podem se apresentar com o mesmo tipo de lesão, como por exemplo: arranhadura do gato, sífilis, tuberculose, fungo (principalmente a candidíase), retinopatia herpética e até mesmo a forma focal da doença de Behçet.

O sucesso do diagnóstico da TOPN, assim como qualquer outro tipo de uveíte, baseia-se no binômio: anamnese e biomicroscopia. Entretanto, deve-se acrescentar a este binômio o rastreamento completo da retina pela oftalmoscopia binocular indireta.

Durante a anamnese, deve-se aprofundar num tópico de grande importância que é a epidemiologia.

À biomicroscopia, deve-se estudar, com zelo, o segmento anterior e posterior, e de um modo mais íntimo, o corpo vítreo (humor vítreo), pois é neste setor que se tem a oportunidade de observar: DVP, precipitados aderidos à face posterior da membrana hialóide posterior, as bursas, a inversão do canal de Cloquet e, fundamentalmente, as características seletivas das células que infiltram o humor vítreo.

Outro setor que oferece elementos para o diagnóstico da TOPN é a biomicroscopia da lesão e de seus elementos coadjuvantes, tais como: árvore vascular, cabeça do nervo óptico e mácula.

O mundo da oftalmologia, principalmente o estudo do segmento posterior do olho, está invadido por inúmeras propedêuticas sofisticadas, que, na vida acadêmica universitária, são elementos importantes para o estudo mais profundo das uveítes. Os exemplos mais importantes são: a ecografia B, ERG, UBM e, atualmente, os elementos componentes da Heidelberg HRA2 - "Red free", "Infra red", Autofluorescência, Angiografia fluoresceínica, Indocianina verde e a Tomografia de Coerência Ótica Espectral.

Como resumo e clausura desta revisão, conclui-se que é mandatório, no sentido de diagnóstico e prognóstico, o estudo, já mencionado e enfatizado anamnese, biomicroscopia e oftalmologia binocular indireta. 


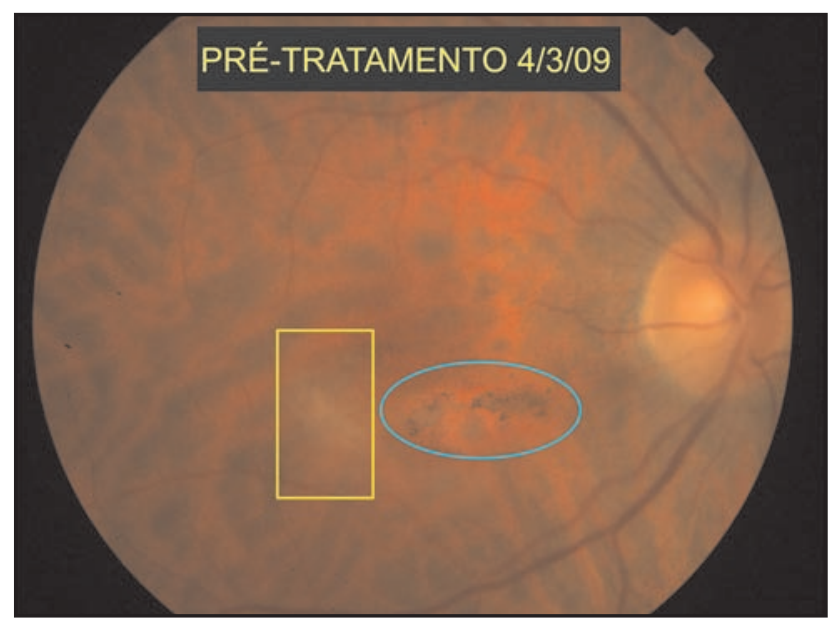

Figura 1 - Retinografia - retângulo amarelo, lesão ativa ( $2^{\mathrm{a}}$ crise), circulo azul - lesão cicatrizada ( $1^{a}$ crise). Azul: lesão retinocoroidiana com áreas de hiperpigmentação. Amarelo:lesão retinocoroidiana, amarelada, com margens imprecisas

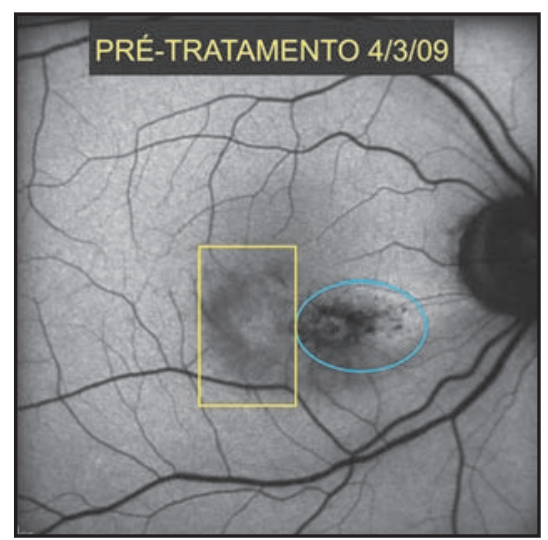

Figura 3 - Angiografia auto-fluorescente retângulo amarelo ( $2^{\mathrm{a}}$ crise $)$, círculo azul ( $1^{\text {a }}$ crise). Autofluorescência: azul - área hipoautofluorescente com margens precisas. Amarela: área hiperautofluorescente central com margens hipoautofluorescentes imprecisas

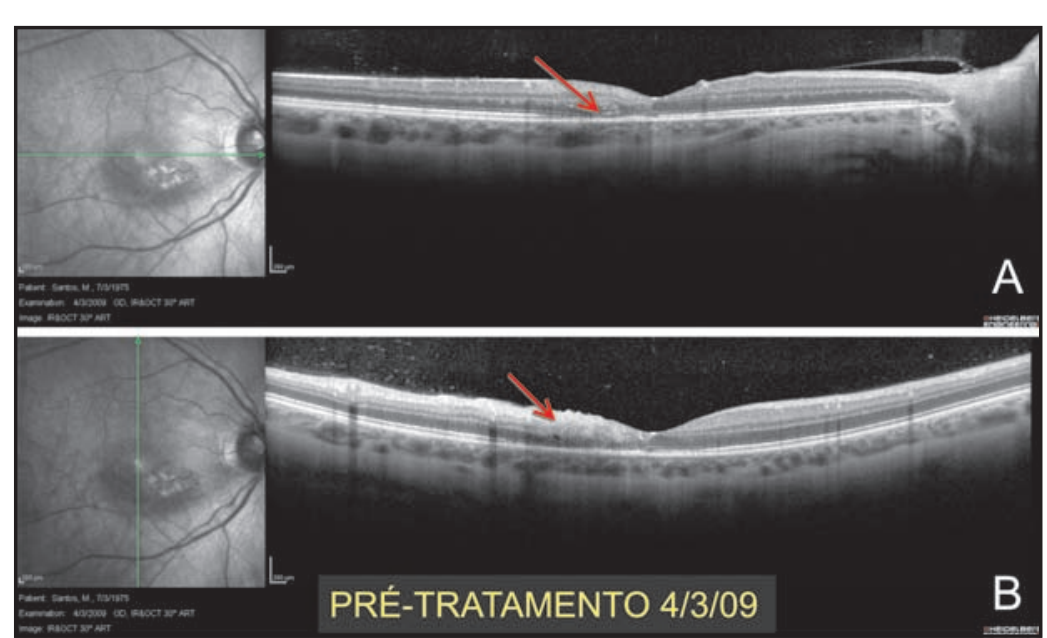

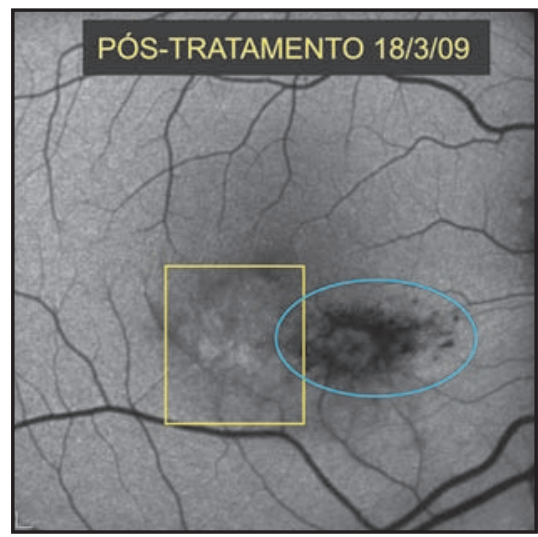

Figura 4 - Angiografia auto-fluorescente retângulo amarelo ( $2^{\mathrm{a}}$ crise $)$, círculo azul $\left(1^{\mathrm{a}}\right.$ crise $)$. Angiografia com scan vertical: fragmentação da camada de fotorreceptores. Angiografia com scan horizontal: cistos intraretinianos

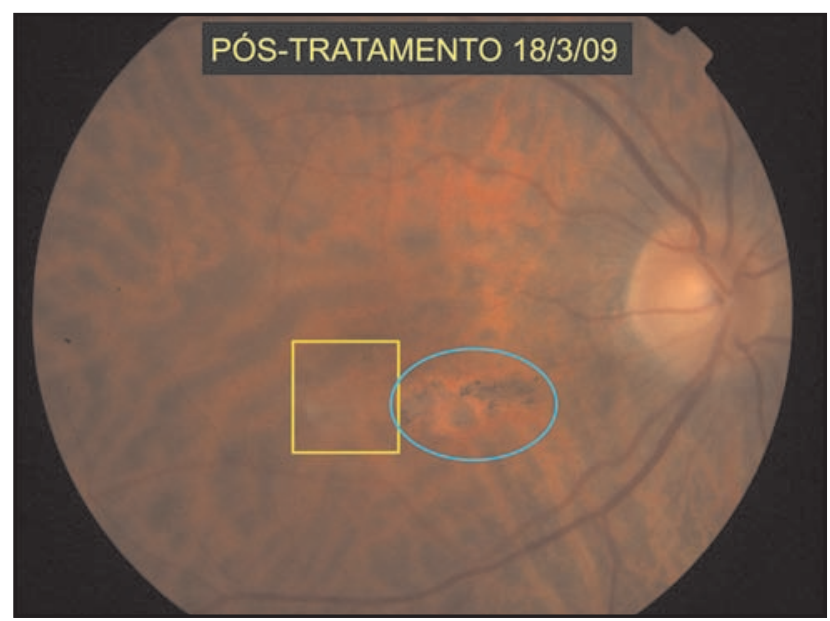

Figura 2 - Retinografia. 18/3 - retângulo amarelo - tênue cicatriz ( $2^{\mathrm{a}}$ crise), Círculo azul - Lesão cicatrizada ( $1^{\mathrm{a}}$ crise $)$. Angiografia com scan vertical: fragmentação da camada de fotorreceptores. Angiografia com scan horizontal: cistos intraretinianos

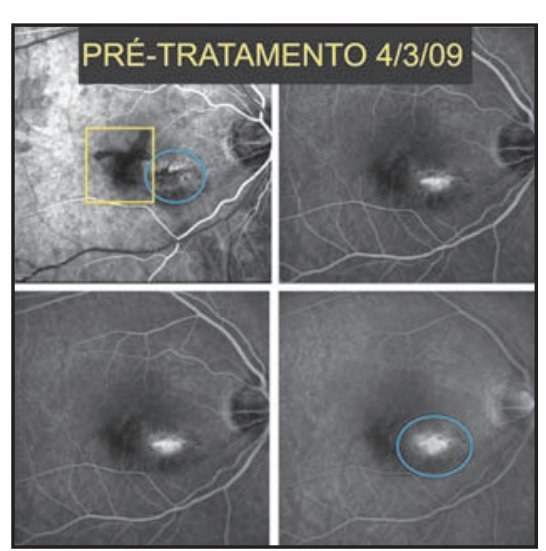

Figura 5 - Angiografia fluoresceínica 4/3. Retângulo amarelo ( $2^{\mathrm{a}}$ crise $)$, círculo azul $\left(1^{\text {a }}\right.$ crise $)$. Angio: Amarelo - área hipofluorescente desde as fases iniciais. Azul: área hiperfluorescente desde as fases iniciais com impregnação tardia
Figura 6 - (A) infrared com SOCT horizontal: aumento de refletividade na camada nuclear interna. (B) infrared com SOCT vertical: aumento de refletividade das camadas internas da retina 


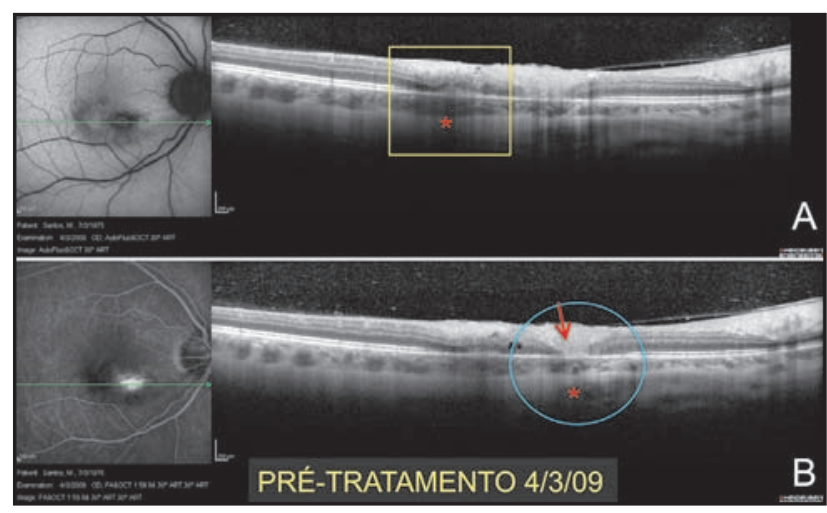

Figura 7 - (A) Autofluorescência com scan horizontal:sombreamento óptico posterior (asterísco). (B) Angiografia com SOCT scan horizontal: desorganização das camadas retinianas (seta), Aumento da refletividade do complexo vascular coroídeo (asterisco)

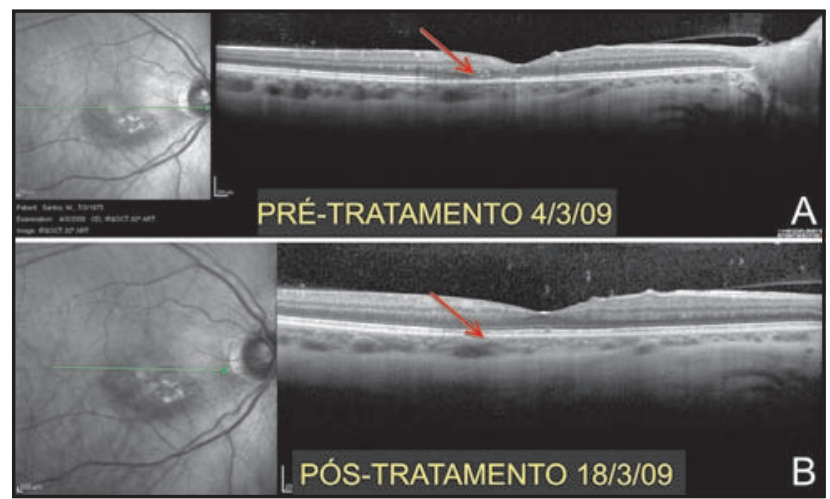

Figura 9- Caso clínico 1 - (A) infrared com SOCT horizontal: aumento de refletividade na camada nuclear interna. (B) infrared com SOCT horizontal: normalização da refletividade na camada nuclear interna. Angiografia com scan vertical: fragmentação da camada do fotorreceptores. Angiografia com scan horizontal: cistos intraretinianos

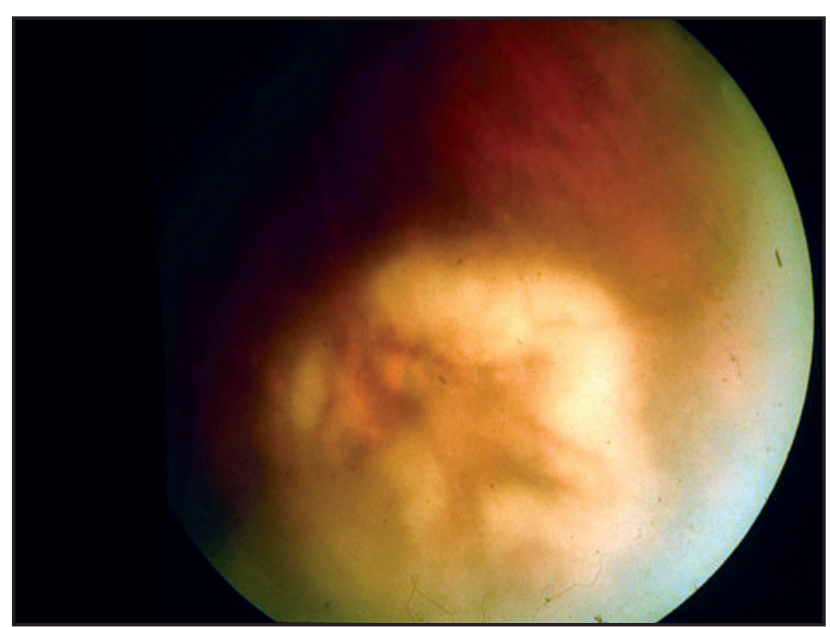

Figura 10 - Caso clínico 2 - ID: I.J.P., masculino, 40 anos. 04/93: Mialgia, febre e hiporexia. 05/93: BAV OE. IgG e IgM positivos para toxoplasmose. IL: 1 mês. Comentários: Pela morfologia e topografia da lesão associada a mínima reação do corpo vítreo, o diagnóstico provável foi de retinopatia herpética necrosante, porém com a sorologia positiva para toxoplasmose o diagnóstico definitivo foi toxoplasmose ocular adquirida

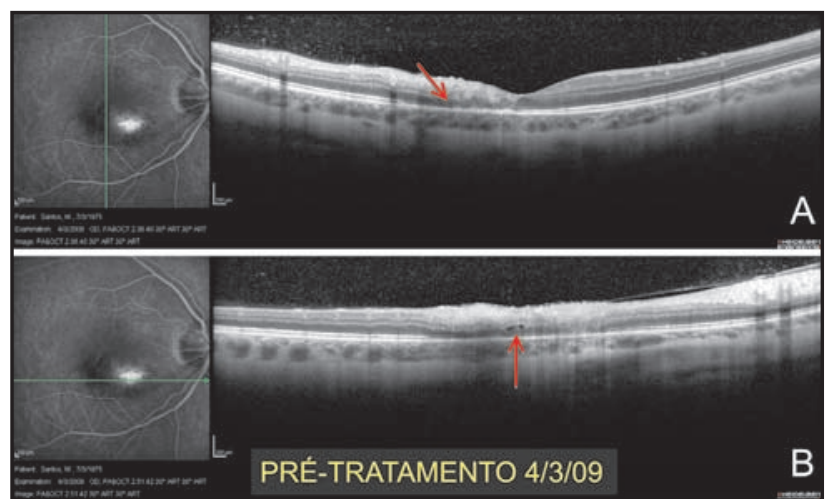

Figura 8 - (A) Angiografia com scan vertical: fragmentação da camada de fotorreceptores, (B) Angiografia com scan horizontal: cistos intraretinianos

\section{REFERÊNCIAS}

1. Ajzenberg, D. et al. Genotype of 86 Toxoplasma gondii isolates associated with human congenital toxoplasmosis, and correlation with clinical findings. J Infect Dis, v.186: p.684689, 2002.

2. Akstein, R.B.; Wilson, L.A.; Teutsch, S.M. Acquired toxoplasmosis. Ophthalmology, v.89: p.1299-1302, 1982.

3. Andrade, G.M.Q. Estudo de prevalência de toxoplasmoseinfecção entre crianças de 0-12 anos de idade matriculadas no Ambulatório Geral de Pediatria do Hospital das Clínicas da UFMG, 1994 (mestrado em pediatria). Universidade Federal de Minas Gerais, 1994.

4. Apinall, T.V. et al. Prevalence of Toxoplasma gondii infection in commercial meat products as monitored by polymerase chain reaction-food for thought? Int J Parasitol, v.32: p.11931199, 2002.

5. Atamaca, L.S.; Simsek, T.; Batioglu, F. Clinical features and prognosis in ocular toxoplasmosis. Jpn J Ophthalmol, v.48: p.386-391, 2004.

6. Azevedo, D.O.M. Triagem neonatal para toxoplasmose congênita no estado de Minas Gerais: resultados do primeiro exame oftalmológico. 2008 (Doutorado em oftalmologia)Faculdade de Medicina, Universidade Federal de Minas Gerais, Belo Horizonte, 2008.

7. Bahia-Oliveira, L. et al. High endemic waterborne toxoplasmosis in North Rio de Janeiro State, Brazil. Emerg Infect Dis, v.9: p.55-62, 2003.

8. Barragan, A.; Sibley, L.D. Transepithelial migration of Toxoplasma gondii is linked to parasite motility and virulence. $\mathbf{J}$ Exp Med, v.195: p.1625-1633, 2002.

9. Benenson, M.W. et al. Oocysts transmitted toxoplasmosis associated with ingestion of contaminated water. N Engl J Med, v.307: p.666-669, 1982

10. Beniz, J. Toxoplasmose ocular adquirida. Arq. Bras. Of talmol, v.56, n.3: p.134-136, 1993.

11. Bonfioli, A.A.; Oréfice, F. Toxoplasmosis. Semin Ophthalmol, v.20: p.129-141, 2005.

12. Bosch-Driessen, E.H.; Rothova, A. Recurrent ocular disease in postnatally acquired toxoplasmosis. Am J Ophthalmol, v.128: p.421-425, 1999.

13. Bosch-Driessen, E.H. et al. Ocular toxoplasmosis. Ophthalmology, v.109: p.869-878, 2002.

14. Bowie, W.R. et al. Outbreak of toxoplasmosis associated with municipal drinking water. Lancet, v.350: p.173-177, 1997.

15. Brezin, A.P.; Cisneros, B. Congenital and acquired infection in ocular toxoplasmosis. In: Annual Meeting of the Association for Research in Vision and Ophthalmology, n.2020,1999. Abstract. 
16. Burnett, A.J. et al. Multiple cases of acquired toxoplasmosis retinitis presenting in an outbreak. Ophthalmology, v.105: p.1032-1037, 1998.

17. Bussaca, A.; Nobrega, P.; Trapp, E. Consideration sur 23 cas de chorioretinite chez dês sujets adultes porteurs d'anticorps toxoplasmiques, Bull Mem Soc Fr Ophthal, v.73: p.306-313, 1950.

18. Calico, I. et al. Isolation of Toxoplasma gondii from immunocompromised patients using tissue culture. Infection, v.19: p.340-342, 1991.

19. Camargo, M.C.V. Epidemiologia da infecção por Toxoplasma Gondii no município de Ribeirão das Neves, MG [Dissertação de Mestrado]. Belo Horizonte: Instituto de Ciências Biológicas, UFMG; 1987. 137p.

20. Camargo, M.E. Improved technique of indirect immunofluorescence for serologica diagnosis of toxoplasmosis. Rev Inst Med Trop São Paulo, v.3: p.117-11, 1964.

21. Camargo, M.E.; Leser, W.S.P. Diagnostic information from serological tests in human toxoplasmosis. I. A comparative study of hemagglutination, complement fixation, IgG and IgM immunofluorescent test in 3752 serum samples. Rev Inst Med Trop S.Paulo, v.18: p.215-226, 1979.

22. Camargo, M.E.; Moura, M.E.; Leser, P.G. Toxoplasmosis serology: an efficient hemagglutination procedure to detect IgG and IgM antibodies. Rev Inst Med Trop São Paulo, v.31, n.4: p.279-285, 1989.

23. Carme, B. et al. Severe acquired toxoplasmosis in immunocompetent adult patients in French Guiana. J Clin Microbiol, v.40, n.11: p.4037-4044, 2002.

24. Cathie, I.A.G. Toxoplasmosis in childhood. Lancet, v.266: p.813814, 1954.

25. Chaves-Caballo, E. Samuel T Darling and human sarcosporidiosis or toxoplasmosis in Panamá. JAMA, v.1: p.87-89, 1970.

26. Chiari, C.; NEVES, D.P. Human toxoplasmosis acquired by ingestion of goat's milk. Mem Inst Oswaldo Cruz, v.79: p.337340,1984

27. Chiquet, C. et al. Toxoplasmose oculaire (panuvéite) après transplantation hépatique. J Fr Ophthalmol, v.23, n.4: p.375379, 2000

28. Conley, F.K.; Jenkins, K.A.; Remington, J.S. Toxoplasma gondii infection of the central nervous system. Hum Pathol, v.12, n.8: p.690-698, 1981.

29. Costa, J.M. et al. Prenatal diagnosis of congenital toxoplasmosis by duplex real-time PCR using fluorescence resonance energy transfer hybridization probes. Prenat Diagn, v.21: p.8588, 2001.

30. Costa, M.I.C. Aspectos clínicos e epidemiológicos da toxoplasmose ocular presumida em zona rural do estado de Minas Gerais (Dissertação de mestrado). Santa Casa de Misericórdia. Belo Horizonte, 2003.

31. Coutinho, S.G. et al. Observações sobre a presença de anticorpos para Toxoplasma gondii em cães de área suburbana do Rio de Janeiro. Rev Bras Soc Med Trop, v.2, n.6: p.285295,2002

32. Coutinho, S.G. et al. Outbreak of human toxoplasmosis in a rural area. A three year serologic follow-up study. Mem Inst Oswaldo Cruz, v.77, n.1: p.29-36, 1982.

33. Coutinho, S.G.; Vergara, R.C. Toxoplasmose . In: COURA, J.R. Dinâmica das doenças infecciosas e parasitárias. $2^{\text {a }}$. ed. Rio de Janeiro: Guanabara Koogan AS, v.1: p.815-832, 2005.

34. Couvreur, J.; Thulliez, P. Acquired toxoplasmosis of ocular or neurologic site: 49 cases. Pesse Med, v.25: p.438-442, 1996.

35. Dannemann, B.R. et al. Differential agglutination test for diagnosis of recently acquired infection with Toxoplasma gondii. J Clin Microbiol, v.28: p.1928-1933, 1990.

36. Dardé, M.L.; Bouteille, B.; Pestre-Alexandre, M. Isoenzime analysis of 35 Toxoplasma gondii isolates and the biological and serological implications. J Parasitol, v.78: p.786-794, 1992.

37. Darling ST. Sarcosporidiose: with report of a case in man. Proc Canal Zone Medd 1908;1:141-152
38. Darrell, R.W. et al. Chorioretinopathy and toxoplasmosis. Arch Ophthalmol, v.71: p.63-68, 1964.

39. Delair, E.; Monnet, D.; Grabar, S.; Dupouy-Camet, J.; YEAR, H.; Brézin, A.P.Respective roles of acquired and congenital infections in presumed oculartoxoplasmosis. Am J Ophthalmol. 2008 Dec;146(6):851-5.

40. Desmonts, G.; Naot, Y.; Remington, J.S. Immunoglobulin MImmunosorbent Agglutination Assay for diagnosis of infectious diseases: diagnosis of acute congenital and acquired toxoplasma infections. J Clin Microbiol, v.14, n.5: p.486-491, 1981.

41. Dobrowolski, J.M.; Sibey, L.D. Toxoplasma invasion of mammalian cells is powered by the action cytoskeleton of the parasite. Cell, v.84: p.933-939, 1996.

42. Dorfman, R.F.; Remington, J.S. Value of lymph-node biopsy in the diagnosis of acute acquired toxoplasmosis. N Engl J Med, v.289: p.878-881, 1973.

43. Dubey, J.P.; Beattie, G. Toxoplasmosis of animals and man. CRC press, p.220, 1988.

44. Dubey, J.P.; Kirkbride, C.A. Economic and public health considerations of congenital toxoplasmosis in lambs. LA Ve Med Assoc, v.195: p.1715-1716, 1989.

45. Dubey, J.P.; Miller, N.L.; Frenkel, J.K. The Toxoplasma gondii oocyst from cat feces. J Exp Med, v.132, p.636-62, 1970.

46. Dubey, J.P. et al. Effect of high temperature on infectivity of Toxoplasma gondii tissue cysts in pork. J Parasitol, v.76: p.201204, 1990.

47. Dubey, J.P. et al. High prevalence of Toxoplasma gondii infection in market weight pigs from a farm in Massachusetts. $\mathbf{J}$ Parasitol, v.88: p.1234-1238, 2002a.

48. Dubey, J.P. et al. Biological and genetic characterization of Toxoplasma gondii isolates from chickens (Gallus domestcus) from São Paulo, Brazil: unexpected findings. Int J Parasitol, v.32: p.99-105, 2002 b.

49. Dubey, J.P. et al. Toxoplasma gondii infection in cats in Paraná, Brazil: seroprevalence, tissue distribution, and biological and genetic characterization of isolates. J Parasitol, v.90: p.721$726,2004$.

50. Dupouy-Camet, J. et al. Detection of Toxoplasma gondii in venous blood from AIDS patients by polymerase chain reaction. J Clin Microbiol, v.31: p.1866-1869, 1993.

51. Fardeau, C. et al. Diagnosis of toxoplasmic retinochoroiditis with atypical clinical features. Am J Ophthalmol, v.134: p.196203, 2002.

52. Fernandes, L.C.; Oréfice, F. Aspectos clínicos e epidemiológicos da uveítes, em serviços de referência em Belo Horizonte 1970-1993, Parte I e Parte II. Rev Bras Oftalmol, v.55: p.569592, 1996.

53. Filisetti, D.; Candolfi, E. Imunne response to Toxoplasma gondii. Ann Ist Super Sanità, v.40: p.71-80, 2004.

54. Frenkel, J.K. Pathogenesis, diagnosis and treatment of human toxoplasmosis. JAMA, v.140: p.369-377, 1949.

55. Frenkel, J.K. Toxoplasmosis: mechanisms of infection. Laboratory diagnosis and management. Curt Top Pathol, v.54: p.27-75, 1971.

56. Frenkel, J.K. Toxoplasmosis. Pediatr Clin North Am, v.32: p.917-932, 1985 .

57. Frenkel, J.K.; Ruiz, A.; Chenchilla, M. Soil survival of toxoplasma oocysts in Kansas and Costa Rica. Am J Trop Med HYg, v.24: p.439, 1975.

58. Friedmann, C.T.; Knox, D.L. Variations in recurrent active toxoplasmic retinochoroiditis. Arch Ophthalmol, v.81: p.481493, 1969.

59. Fuentes, I. et al. Gaenotypic characterization of Toxoplasma gondii strains associated with human toxoplasmosis in Spain: direct analysis from clinical samples. J Clin Microbiol, v.39: p.1566-1570, 2001.

60. Garcia, C.A.A. et al. Socioeconomic conditions as determining factors in the prevalence of systemic and ocular toxoplasmosis in Northeastern Brazil. Ophthalmic epidemiology, v.11, n.4: p.301-317, 2004. 
61. Garweg, J.G.; Jacquier, P.; Boehnke, M. Early humor analysis in patients with human ocular toxoplasmosis. J Clin Microbiol, v.38, n.3: p.996-1001, 2000.

62. Garweg, J.G.; Sscherrer, J.N.; Halberstadt, M. Recurrence characteristics in European patients with ocular toxoplasmosis. $\mathrm{Br}$ J Ophthalmol. 2008 Sep;92(9):1253-6.

63. Gazzinelli, R.T.; Denkers, E.Y.; Sher, A. Host resistance to Toxoplasma gondii: model for studying the selective induction of cell-mediated immunity by intracellular parasites. Infect Agents Dis, v.2: p.139-149, 1993.

64. Gilbert, R.E.; Standford, M.R. Is ocular toxoplasmosis caused by prenatal or postnatal infection? Br J Ophthalmol, v.84: p.224-226, 2000 .

65. Glasner, P.D.; Silveira, C.; Kruszon-Moran, D. An unusually high prevalence of ocular toxoplasmosis in southern Brazil. Am J Ophthalmol, v.114: p.136-144, 1992.

66. Goldman, M. Staining Toxoplasma gondii with flurescein-labelled antibody: II. A new serologic test for antibodies to Toxoplasma based upon inhibition of specific staining. J Exp Med, v.105, n.6: p.557-573, 1957.

67. Gómez-Marin, J.E. et al. Frequency of Specific anti-Toxoplasma gondii $\operatorname{lgM}, \lg \mathrm{A}$ and $\mathrm{IgE}$ in Colombian Patients with Acute and Chronic Ocular Toxoplasmosis. Mem Inst Oswaldo Cruz, v.95, n.1: p.89-94, 2000.

68. Gonçalves, E.C. et al. Toxoplasmose ocular adquirida. Relato de 3 casos simultâneos em membros da mesma família. Rev Bras Oftalmol, v.54: p.57-60, 1995.

69. Gords, L. Dinâmica da transmissão das doenças. In: Epidemiologia.2. ed. Rio de Janeiro. Revinter, p.14-30, 2004.

70. Graff, M.J.; Russel, S.R. Acquired ocular toxoplasmosis: 42 year-old female with "fuzzy" vision for two weeks. Eye rounds. org 2007. Disponível em: <http://webeye.ophth.uiowa.edu/ eyeforum/cases/74-Acquired-Toxoplasmosis-Retina.htm>. Acesso em 11.08.08

71. Guerra, M.R.L. Aspectos epidemiológicos da toxoplasmose humana em Belo Horizonte, MG [Tese de Doutroado]. Belo Horizonte: Instituto de Ciências Biológicas, UFMG; 1985.83 p.

72. Hassene, A. et al. Case report Acquired toxoplasmosis presenting as polymyositis and chorioretinitis in immunocompetent patient. Joint Bone Spine, v.20: p.1-3, 2008.

73. Hausmann, N.; Richard, G. Acquired ocular toxoplasmosis. A fluorescein angiography study. Ophthalmol, v.98: p.1647-1651, 1991.

74. Hegab, S.M.; Mutawa, S.A Immunopathogenesis of toxoplasmosis. Clin Exp Med, v.03: p.84-105, 2003.

75. Heidelman, J.M. Evaluation of toxoplasma neutralization tests in cases of chorioretinitis. Arch Ophthalmol, v.34: p.28-39, 1945.

76. Hennequin, C.; Dureau, P.; N'Guyen, L. Congenital toxoplasmosis acquired from an immune woman. Pediatr Infect Dis J, v.16: p.75-77, 1997.

77. Hill, D.; Dubey, J.P. Toxoplasma gondii: transmission, diagnosis and prevention. Clin Microbiol Infect, v.8: p.634-640, 2002.

78. Hogan, M.J. Ocular toxoplasmosis: XIV Edward Jackson Memorial Lecture. Am J Ophthalmol, v.46: p.467-494, 1958.

79. Hogan, M.J. Ocular toxoplasmosis in adult patients. In: Maumenee, A.E. Toxoplasmosis, Baltimore: Williams \& Wilkins, p.935-942, 1962.

80. Hogan, M.J.; Kimura, S.J. Ocular toxoplasmosis. Arch Ophthalmol, v.72: p.592-600, 1964.

81. Holland, G.N.; Crespi, C.M.; Ten Dam-Van Loon, N.; Charonis, A.C.; YU, F.; Bosch-Driessen, L.H.; Rothova, A. Analysis of recurrence patterns associated with toxoplasmic retinochoroiditis.

82. Am J Ophthalmol. 2008 Jun;145(6):1007-1013.

83. Holland, G.N.; Jackson, L.X.E. Memorial Lecture. Ocular toxoplasmosis: A global reassessment. Part I: Epidemiology and course of disease. Am J Ophthalmol, v.136: p.973-988, 2003.

84. Holland, G.N. et al. Toxoplasmosis. In: PEPOSE, J.S.; Holland, G.N.; Wilhelmus, K.R. (eds). Ocular Infection and Immunity. St. Louis, MO: Mosby, p.1183-1223, 1996.
85. Holland, G.N. et al. Intraocular inflammatory reactions without focal necrotizing retinochoroiditis, in patients with acquired systemic toxoplasmosis. Am J Ophthalmol, v.128: p.413420, 1999a.

86. Holland, G.N. et al. Reconsidering the pathogenesis of ocular toxoplasmosis. Am J Ophthalmol, v.128: p.502-505, 1999b.

87. Howe, D.K. et al. Determination of genotypes of Toxplasma gondii strains isolated from patients with toxoplasmosis. J Clin Microbiol, v.35: p.1411-1414, 1997.

88. Howe, D.K.; Sibley, L.D. Toxoplasma gondii comprises three clonal lineages: correlation of parasite genotype with human disease. J Infect Dis, v.172: p.1561-1566, 1995.

89. Jamra, L.M.F.; Guimarães, E.C. Conversão sorológica para toxoplasmose em crianças de um Centro de Saúde de São Paulo. Rev Inst Med Trop S. Paulo, v.23, n.3: p.33-7, 1981.

90. Janku, J. Pathogenesis ands pathologic anatomy of coloboma of macula lútea in eye of normal dimensions and in microphthalmic eye, with parasites in retina. Cas Lek Cesk, v.62: p.1021-1143, 1923.

91. Jeannel, D. et al. Epidemiology of toxoplasmosis among pregnant women in the Pris area. Int J Epidemiol, v.17: p.595-602, 1988.

92. Jones, J.L. et al. Toxoplasma gondii infection in the United States: seroprevalence and risk factors. Am J Epidemiol, v.154, n.4: p.357-365, 2001

93. Jones, L.A.; Alexander, J.; Roberts, W. Ocular toxoplasmosis: in the storm of the eye. Parasite Immunology, v.28: p.635$642,2006$.

94. Joyson, D.H. Epidemiology of toxoplasmosis in U.K. Scand J Infect Dis Suppl, v.84: p.65-69, 1992.

95. Kamazoe, U. In: Neves, D.P. Parasitogia humana, 9.ed, São Paulo: Atheneo, p.174-187, 1995.

96. Kean, B.H.; Kimball, A.C.; Christensen, W.N. An epidemic of acute toxoplasmosis. JAMA, v.208: p.1002-1004, 1969.

97. Klaren, V.N.A.; et al. Differences between intraocular and serum antibody responses in patients with ocular toxoplasmosis. Am J Ophthalmol, v.126: p.698-706, 1998.

98. Koch, F.L.P. et al. Toxoplasmic encephalomyelitis. Arch Ophthalmol, v.29: p.1-25, 1943.

99. Kotula, A.W. et al. Effect of freezing on efetivity of Toxoplasma gondii. J Parasitol, v.46: p.11-21, 1991.

100. Krick, J.A.; Remington, J.S. Current concepts in parasitology toxoplasmosis in the adult. N Engl J Med, v.10: p.1110-1114, 1989.

101. Laveran, M. Au sujet de l'hematozoaire endoglobulaire de Padda Oryzivora.C.R. Seances. Soc Biol Fil, v.52: p.19-20, 1900.

102. Leblanc, A. et al. Acquired toxoplasmic chorioretinitis with a late onset. Arch Fr Pediatr, v.42: p.37-39, 1985.

103. Lehmann, T. et al. Strain typing of Toxoplasma gondii: comparison of antigen-coding and housekeeping genes. J Parasitol, v.86: p.960-971, 2000.

104. Lieb, D.F. et al. Acquired toxoplasma retinitis may present similarly to unilateral acute idiopathic maculopathy. Am J Ophthalmol, v.137: p.940-942, 2004.

105. Liesenfeld, O. et al. Effect of testing for $\mathrm{IgG}$ avidity in the diagnosis of Toxoplasma gondii infection in pregnant women: experience in USA reference laboratory. J Infect Dis, v.183: p.1248-1253, 2001.

106. Liesenfeld, O. et al. False-positive results in immunoglobulin $\mathrm{M}(\mathrm{IgM})$ toxoplasma antibody tests and importance of confirmatory testing: the Platelia toxo IgM test. J Clin Microbiol, v.35: p.174-178, 1997.

107. Logar, J. et al. Seroprevalence of toxoplasma antibodies among patients with ocular disease in Slovenia. J Inf, p.74, 2002 [letter].

108. Luft, B.J.; Billingham, M.; Remington, J.S. Endomyocardial biopsy in the diagnosis of toxoplasmic myocarditis. Transplant Proc, v.18: p.1871-1873, 1986.

109. Luft, B.J.; Remington, J.S. Acute toxoplasma infection among family members of patients with acute lymphadenopathic toxoplasmosis. Arch Intern Med, v.144: p.53-56, 1984. 
110. Lynch, M.I.; Moraes, L.F.; Malagueño, E.; Ferreira, S.; Cordeiro, F.; Oréfice, F. [Clinical characteristics of 64 individuals carrying active posterior presumptively toxoplasmic uveitis, in Pernambuco]. Arq Bras Oftalmol. 2008 Jan-Feb;71(1):43-8.

111. Lynch, M.I. Validação do teste de IgA secretora específica da lágrima em portadores de uveítes posterior ativa presumivelmente por Toxoplasma gondii. 2007 (Doutorado em Medicina Tropical) - Universidade Federal do Pernambuco, Recife, 2007.

112. Lynfield, R.; Guerina, N.G. Toxoplasmosis. Pediatr Rev, v.18, n.3: p.75-83, 1987.

113. Maestrini, A.A. Aspectos clínicos e epidemiológicos da toxocaríase da população escolar do município de Rio Acima - Região Metropolitana de Belo Horizonte-Minas Gerais (Doutorado em Oftalmologia). Belo Horizonte-MG. Faculdade de Medicina.Universidade Federal de Minas Gerais, Minas Gerais, 1995.

114. Mansur, H.; Jones, T.C.; Lempert, J.A. Toxoplasmosis in a family and documentation of acquired retinochoroiditis. Am J Med, v.64: p.396-402, 1978.

115. Melamed, J. Acquired ocular toxoplasmosis: late onset. Advances in ocular immunology, p.449-451, 1994.

116. Melamed, J. Retinocoroidite toxoplásmica (Doutorado em Oftalmologia). Faculdade de Medicina, Universidade Federal de Minas Gerais, Belo Horizonte, 1991.

117. Mele, A. et al. Toxoplasmosis in bone marrow transplantation: A report of two cases and systematic review of the literature. Bone Marrow Transplant, v.29: p.691-698, 2002.

118. Michelson, J.B. et al. Retinitis secondary to acquired systemic toxoplasmosis with isolation of the parasite. Am J Ophthalmol, v.86, n.4: p.548-552, 1978.

119. Montoya, J.G. Laboratory diagnosis of Toxoplasma gondii infection and toxoplasmosis. J Infect Dis, v.185(Suppl 1): p.S73-82, 2002.

120. Montoya, J.G.; Kovacs, J.A.; Remington, J.S. Toxoplasma gondii. In: Mandell, G.L.; Bennett, J.E.; Dolin, R. Principles and practice of infectious diseases. 6th ed. Pennsylvania: Churchill Livingstone, v.3: p.3170-3198, 2005.

121. Montoya, J.G.; Liesenfeld, O. Toxoplasmosis. Lancet, v.363: p.1965-76, 2004.

122. Montoya, J.G.; Remington, J.S. Toxoplasmic choriorretinitis in setting of acute acquired toxoplasmosis. Clin Inf Dis, v.23: p.277-282, 1996.

123. Montoya, J.G. et al. Toxoplasmic myocarditis and polymyositisin patients with acute acquired toxoplasmosis. Clin Infect Dis, v.24: p.676-683, 1997.

124. Montoya, J.G. et al. Use of the polymerase chain reaction for diagnosis of ocular toxoplasmosis. Ophthalmology, v.106: p.1554-1563, 1999.

125. Mossmann, T.R. Regulation of immune responses by T cells with different cytokine secretion phenotypes:role of a new cytokine, cytokine synthesis inhibitory factor (IL10). Int Arch Allergy Appl Immunol, v.94, n.1-4: p.110-115, 1991.

126. Moura, L. et al. Waterborne toxoplasmosis, Brazil, from field to gene. Emerging Infect Dis, v.12, n.2: p.326-329, 2006.

127. Mullan, D.P.; Henry, L.; Beverly, J.K. Toxoplasmosis and myocarditis. Br Med J, v.4, n.5630: p.559-560, 1968.

128. Nicole, C.; Manceaux, L. Sur une infection corps de Leishman (ou organisms voisins) du gondii: on an infection by Leishman bodies in the gondii. Compt rend acad de sc, v.147: p.763-766, 1908.

129. Nussenblatt, R.B.; Belfort, R. Ocular toxoplasmosis: An old disease revisited. Jama, v.271, v.4: p.304-307, 1994.

130. O'Connor, G.R.Precipitating antibody to toxoplasma: a follow-up study on findings in the blood and aqueous humor. Am J Ophthalmol, v.44: p.75-85, 1957.

131. Onadeko, M.O.; Joyson, D.H.; PAYNE, R.A. The prevalence of Toxoplasma infection among pregnant women in Ibadan, Nigéria. J Trop Med Hyg, v.95: p.143-145, 1992.

132. Ongkosuwito, J.V. et al. Serologic evaluation of patients with primary and recurrent ocular toxoplasmosis for evidence of recent infection. Am J Ophthalmol, v.128: p.407-413, 1999.
133. Oréfice, F.; Bahia-Oliveira, L.M.G. Toxoplasmose. In: Oréfice, F. Uveíte clínica e cirúrgica. 2. ed. Rio de Janeiro: Cultura Médica, v.2, p.699-804, 2005.

134. Oréfice, F.; Tonelli, E. Toxoplasmose adquirida ganglionar associada à uveíte anterior granulomatosa sem retinocoroidite. Rev Bras Oftalmol, v.54 (12):p.21-24,1995.

135. Oréfice, F.; Barboza, A.L.; Campos, W.R.; Oréfice, J.L.; Costa, R.A.; Lucy H.; Young, L.H. Acquired ocular toxoplasmosis in Brazilian Patients. ARVO 2009 (Poster).

136. Palanisamy, M. et al. Outbreak of ocular toxoplasmosis in Coimbatore, Índia. Indian J Ophthalmol, v.54, n.2: p.129-131, 2006.

137. Palkovacs, E.M.; Correa, Z.; Augsburger, J.J.; EAGLE, R.C. Jr. Acquired toxoplasmic retinitis in an immunosuppressed patient: diagnosis by transvitreal fine-needle aspiration biopsy. Graefes Arch Clin Exp Ophthalmol. 2008 Oct;246(10):1495-7.

138. Perkins, E.S. Ocular toxoplasmosis. Br J Ophthalmol, v.57: p.1-17, 1973.

139. Pinheiro, S.R.A.A. et al. Estudo da toxoplasmose ocular em famílias de pacientes portadores de toxoplasmose congênita, sistêmica e ocular. Arq Bras Oftal, v.53: p.4-6, 1990.

140. Pinketon, H.; Henderson, R.G. Adult toxoplasmosis: a previously unrecognized disease entity simulating the typhus-spotted fever group. JAMA, v.116: p.807-814, 1941.

141. Pomeroy, C.; Filice, G.A. Pulmonary toxoplasmosis: A review. Clin Infect Dis, v.14, n.4: p.863-870, 1992.

142. Ramchandani, M. et al. Acquired ocular toxoplasmosis in pregnancy. Br J Ophthalmol, v.86: p.930-943, 2002.

143. Rehder, J.R. et al. Acute unilateral toxoplasmic iridocyclitis in an AIDS patient. Am J Ophthalmol, v.106: p.740-741, 1988 [letter].

144. Remington, J.S. Toxoplasmosis and congenital infection. Intra-uterine infection. Birth defects. Original Article Series, v.4: p.47-56, 1968.

145. Remington, J.S. Toxoplasmosis in adult. Bull NY Acad Med, v.50: p.211, 1974

146. Remington, J.S. et al. Toxoplasmosis. In: Remington, J.S.; KleinN, J. eds. Infectious diseases of the fetus and newborn infants. Philadelphia: WB Saunders, p.205-346, 2001.

147. Roberts, F. et al. Histopathological features of ocular toxoplasmosis in the fetus and infant. Arch Ophthalmol, v.119: p.51-58, 2001.

148. Roldan, E.O.; Moskowitz, L.; Hensley, G.T. Pathology of the heart in acquired immunodeficiency syndrome. Arch Pathol Lab Med, v.111: p.943-946, 1987.

149. Ronday, M.J. et al. Presumed acquired ocular toxoplasmosis. Arch Ophthalmol, v.113: p.1524-1529, 1995.

150. Ross, R.D. et al. Presumed acquired ocular toxoplasmosis in deer hunters. Retina, v.21: p.226-229, 2001.

151. Rothova, A. Ocular involvement in toxoplasmosis. Br J Ophthalmol, v.77: p.371-377, 1993.

152. Ryning, F.W.; LeMeod, R.; Maddox, J.C. Probable transmission of Toxoplasma gondii by organ transplantation. Ann Intern Med, v.90: p.47-79, 1979.

153. Sabin, A.B.; Feldman, H.A. Dyes as microchemical indicators od a new immunity phenomenon affecting a protozoon parasite (Toxoplasma). Science, v.108: p.660-663, 1948.

154. Siegel, S.E.; Lunde, M.N.; Gelderman, A.H. Transmission of toxoplasmosis by leukocyte transfusion. Blood, v.37: p.388394, 1971

155. Siim, J.C. Epidemiological aspects of toxoplasmosis. TR. Sixty Internat Cong Pediat, Anais, v.6: p.356-367, 1950.

156. Silveira, C. et al. Acquired toxoplasmic infection as the cause of toxoplasmic retinochoroiditis in families. Am J Ophthalmol, v.106, n.3: p.362-364, 1988.

157. Silveira, C. et al. A follow-up study of Toxoplasma gondii infection in southern Brazil. Am J Ophthalmol, v.131, n.3: p.351-354, 2001.

158. Silveira, C. et al. The effect of long-term intermittent trimetropim-Sulfamethoxazole treatment on recorrences of toxoplasmic retinochoroiditis. Am J Ophthalmol, v.134: p.4146, 2002 
159. SIMITCH, T. et al. Infection of chicken eggs by T. gondii. Bull Acad Vet Fr, v.39, n.1: p.47-51, 1966

160. Siqueira, R.C.; Jorge, R.; Figueiredo, L.T.M. Bilateral acute acquired toxoplasmic retinochoroiditis after steroid therapy for hantavirus pulmonary syndrome: case report. Arq Bras Oftalmol, v.70: p.513-516, 2007.

161. Souza, W.J.S. et al. Epidemiological aspects of toxoplasmosis in schoolchildren residing in localities with urbano rural characteristics within the city of Rio de Janeiro, Brazil. Mem Inst Oswaldo Cruz, v.82, n.4: p.475-82, 1987.

162. Splendore, A. Um nuovo protozoa parasita dei conigli: incontrato nrll lesione anatomichr d'une malattia che ricorda in molti punti il kala-azar dell'umo. Rev Soc Sci, São Paulo, v.3: p.109-112, 1908.

163. Stagno, S.; Dykes, A.C.; Amos, C.S. An outbreak of toxoplasmosis linked to cats. Pediatrics, v.65: p.706-712, 1980.

164. Stepick-Biek, P. et al. IgA antibodies for diagnosis of acute congenital and acquired toxoplasmosis. J Infect Dis, v.162: p.270-73, 1990.

165. Stehling, A.R.; Oréfice, F. Toxoplasmose ocular adquirida (relato de seis casos com aspectos clínicos diferentes). Rev Bras Oftalmol, v.55, n.6: p.455-465, 1996.

166. SU, C. et al. Indentification of quantitative trait loci controlling acute virulence in Toxoplasma gondii. Proc Natl Acad Sci USA, v.88: p.10753-10758, 2002.

167. Suzuki, Y. Host resistence in the brain against Toxoplasma gondii. J Infect Dis, v.185, n.1: p.S58-65, 2002.

168. Teusch, S.M. et al. Epidemic toxoplasmosis associated with infected cats. N Engl J Med, v.300: p.695-699, 1979.

169. Toellner, K.M. et al. T helper 1 and 2 characteristics start to develop during $\mathrm{T}$ cell ptiming and rare associated with an immediate ability to induce. J Exp Med, v.187: p.1193-1204, 1998.

170.Torres, C.M. Sur une nouvelle maladie de l'homme, caracteriseè par la presence d'in parasite intracellulaire três proche du toxoplasme et musculaire cardiaque, lês muscles du squelette, le tissu cellulaire sous cutane et le tissu nerveux. C R Seances Soc Biol Fil, v.97: p.1778, 1927.
171. Ustun, S. et al. Frequency of toxoplasmosis in patients with cirrhosis. World J Gastroenterol, v.10, n.3: p.452-454, 2004.

172.Vail, D.; Strong, J.J.C.; Stepheson, W.V. Choriorretinitis associated with positive serologic tests for toxoplasma in older children and adults. Am J Ophthalmol, v.26: p.133141,1943

173. Viegas, C.L. et al. Toxoplasmose com comprometimento pulmonar. J Pneumol, v.28, n.4: p.241-243, 2002.

174. WALTON, B.C. Seroepidemiologyn of toxoplasmosis. J Parasitol, v.57: p.115-120, 1971.

175. Webb, R.M.; TABBARA, K.F.; O'CONNOR, G.R. Retinal vasculitis in ocular toxoplasmosis in nonhuman primates. Retina, v.4: p.182-188, 1984.

176. Weiss, L. et al. Infrequent detection of Toxoplasma gondii genome in toxoplasmic lymphadenitis: A polymerase chain reaction study. Hum Pathol, v.23: p.154-158, 1992.

177. Wilder, H.C. Toxoplasma choriorretinitis in adults. Arch Ophthalmol, v.48: p.127-136, 1952.

178. Wising, P. Akut adult toxoplasmos med Lymphadenopathi och chorioretinit. Nod Med, v.47: p.563-565, 1952.

179. Witmer, R. Periodic ophthalmia in horses. Am J Ophthalmol, v.37: p.243-253, 1954.

180. Wolf, A.; Cowen, D.; Paige, B.J. Human toxoplasmosis: occurrence in infants as an encephatomyelitis; verification by transmission to animals. Science, v.89: p.226-227, 1939.

\section{Endereço para correspondência \\ Fernando Oréfice}

R. Espírito Santo, no 1634 - apto. 102, Lourdes

CEP 30160-031- Belo Horiznte - MG

E-mail: f.orefice@terra.com.br 